\title{
Cloud Effects on Meridional Atmospheric Energy Budget \\ Estimated from Clouds and the Earth's Radiant Energy System (CERES) Data
}

\author{
Seiji Kato ${ }^{1}$, Fred G. Rose ${ }^{1}$, David A. Rutan ${ }^{1}$, and Thomas P. Charlock ${ }^{2}$ \\ ${ }^{1}$ Science Systems \& Applications Inc. \\ Hampton, Virginia 23681-2199 \\ ${ }^{2}$ Climate Science Branch \\ NASA Langley Research Center
}

Corresponding author address:

\author{
Seiji Kato \\ Mail Stop 420 \\ NASA Langley Research Center \\ Hampton, Virginia 23681-2199 \\ e-mail: seiji.kato@nasa.gov
}

Submitted to Journal of Climate, April 2007

Revised, September, 4 2007, December, 18 2007, and December, 312007 


\section{Abstract}

The zonal mean atmospheric cloud radiative effect, defined as the difference of the topof-atmosphere (TOA) and surface cloud radiative effects, is estimated from three years of Clouds and the Earth's Radiant Energy System (CERES) data. The zonal mean shortwave effect is small, though it tends to be positive (warming). This indicates that clouds increase shortwave absorption in the atmosphere, especially in midlatitudes. The zonal mean atmospheric cloud radiative effect is, however, dominated by the longwave effect. The zonal mean longwave effect is positive in the tropics and decreases with latitude to negative values (cooling) in polar regions. The meridional gradient of cloud effect between midlatitude and polar regions exists even when uncertainties in the cloud effect on the surface enthalpy flux and in the modeled irradiances are taken into account. This indicates that clouds increase the rate of generation of mean zonal available potential energy. Because the atmospheric cooling effect in polar regions is predominately caused by lowlevel clouds, which tend to be stationary, we postulate that the meridional and vertical gradients of cloud effect increase the rate of meridional energy transport by dynamics in the atmosphere from midlatitude to polar region, especially in fall and winter. Clouds then warm the surface in polar regions except in the Arctic in summer. Clouds, therefore, contribute in increasing the rate of meridional energy transport from midlatitude to polar regions through the atmosphere. 


\section{Introduction}

Clouds perturb the net top-of-atmosphere (TOA) irradiance from that of clear-sky conditions (e.g. Ramanathan et al. 1989). The spatial distribution of radiation deposited to the earth generates the temperature gradient. General circulations reduce the meridional temperature gradient by transporting the energy poleward. Because dynamics is driven by the temperature gradient, it is postulated that poleward energy transport by dynamics is likely to be affected by the presence of clouds. Stuhlmann and Smith (1988) showed, using climatological low and mid level clouds, that both cloud types contribute to an increase in the rate of generation of zonal available potential energy in mid-latitude and polar regions. Because only a part of available potential energy is converted to kinetic energy (Peixoto and Oort 1992), this does not necessarily means that clouds increase the rate of poleward energy transport. Zhang and Rossow (1997) estimated the effect of clouds on meridional energy transport from the International Satellite Cloud Climatology Project (ISCCP, Schiffer and Rossow 1983) global radiative flux dataset. They concluded that clouds enhance meridional energy transport by the atmosphere and reduce the transport by the ocean. Zhang and Rossow (1997), however, did not consider the surface latent heat and sensible heat flux effects in estimating cloud effects on meridional energy transport. Sohn and Smith (1992) discussed the effect of cloud type on the meridional circulation but they did not explicitly compute the zonal mean atmospheric cloud effect. Randall et

al. (1989) used a general circulation model to estimate the effect of the atmospheric cloud radiative effect. They concluded that the atmospheric cloud radiative effect over oceans intensify Hadley circulation, tropical easterlies, and subtropical westerly jets. 
In this study, we use TOA and surface shortwave and longwave irradiances from Clouds and the Earth's Radiant Energy System (CERES, Wielicki et al. 1996) data and estimate the zonal mean cloud radiative effect at the TOA and surface and to the atmosphere. We also include the cloud effect on the surface latent and sensible heat fluxes (enthalpy flux) using the National Center for Environmental Prediction (NCEP) reanalysis (Kalnay et al. 1996) to analyze zonal mean atmospheric cloud effect on the meridional energy transport by the atmosphere quantitatively. We then investigate the atmospheric cloud effect by cloud height and optical thickness so that the effect on meridional energy transport, especially from midlatitude to polar regions, can be understood.

\section{Method}

\subsection{CERES Data and Daily and Monthly Averaging}

CERES data from the Terra satellite taken from March 2000 through February 2003 are used in this study. TOA and surface irradiances are computed by a two-stream model (Fu and Liou 1993; Kato et al. 2005) by forcing the agreement of the TOA irradiance with that derived from CERES radiance measurements by angular distribution models (Loeb et al. 2005; Kato and Loeb 2005). Inputs to the two-stream model are MODIS derived cloud and aerosol properties, MODIS-derived surface skin temperature, ozone amounts (Yang et al. 2000), and temperature and relative humidity profile from the Goddard EOS Data Assimilation System (GEOS-4, Bloom et al. 2004). Six hour and $1^{\circ} \times 1^{\circ}$ GEOS-4 maps are linearly interpolated in space and time for the CERES overpass time and location. When MODIS-derived aerosol properties are not available, modeled aerosol properties by a transport model (Model of Atmospheric Transport and Chemistry, MATCH Collins et 
al. 2001) are used. The ocean spectral surface albedo is from Jin and Stamnes (1994). Broadband land surface albedos are inferred from the clear-sky TOA albedo derived from CERES measurements (Charlock et al. 2006). More detailed descriptions of the irradiance computation in the CERES project are found in Charlock et al. (2006). TOA modeled irradiances are constrained to match CERES-derived irradiances by altering mainly cloud properties by the method described in Rose et al. (1997). Those instantaneous irradiances are included in a CERES product called Cloud and Radiative Swath (CRS). The edition 2B, which is available from the NASA Langley Atmospheric Science Data Center, is used in this study.

We convert instantaneous irradiances to daily mean irradiances by the method described in Appendix A. The underlying assumption in the process is that meteorological conditions do not change over the course of a day. The error in the daily value, therefore, depends on the actual diurnal variation of albedo and transmittance. For example, a systematic diurnal variation of water vapor or cloud amount that is not sampled at the overpass time $(\approx 10: 30 \mathrm{AM})$ is not considered in our estimate. In addition, the solar zenith dependent transmittance is estimated by averaging instantaneous transmittance computed for the overpass time as a function of solar zenith angle and scene type. Because Terra is on a sun-synchronous orbit, the transmittance for large solar zenith angles is from high latitude regions. Surface irradiance near sunrise and sunset at low latitude regions is, therefore, computed using transmittance derived from high latitude regions. As a consequence, the daily downward surface irradiance in low latitude regions is overestimated. In addition, no effort is made to correct the instantaneous longwave irradiance for the daily 
value; we simply averaged daytime and nighttime values weighted by the day-night fraction. We estimate the error in shortwave and longwave surface irradiances by comparing with surface observations in sections 3.2 and 3.5 .

\section{Results}

\subsection{Zonal Net Irradiance}

We define the net shortwave and longwave irradiances at the top of the atmosphere and surface as the downward minus upward irradiance,

$$
F_{s w}^{x}=F_{s w, d n}^{x}-F_{s w, u p}^{x},
$$

and

$$
F_{l w}^{x}=F_{l w, d n}^{x}-F_{l w, u p}^{x},
$$

where the superscript $x$ is either $s f c$ or TOA. The net irradiances are, therefore, positive when the radiative energy is deposited to the system. The net irradiance $F_{\text {rad }}$ is the sum of the net shortwave and net longwave irradiances,

$$
F_{r a d}^{x}=F_{s w}^{x}+F_{l w}^{x} .
$$

Net radiative energy deposition to the atmosphere is given by the net irradiance at TOA minus the net irradiance at the surface,

$$
F_{y}^{a t m}=F_{y}^{T O A}-F_{y}^{s f c},
$$

where the subscript $y$ is $s w, l w$, or rad.

The net shortwave irradiance of the atmosphere $F_{s w}^{a t m}$, which is the shortwave absorption by the atmosphere, is primarily a function of solar zenith angle (Figure 1a). The 
seasonal mean net shortwave irradiance of the atmosphere shown in Figure 1a increases toward the tropics. However, the absorbed irradiance by the atmosphere in the summer hemisphere is nearly constant with latitude and rarely exceeds $100 \mathrm{Wm}^{-2}$ (Figure 1a). When $F_{s w}^{a t m}$ is divided by the daily mean insolation at TOA, the seasonal mean shortwave absorptance of the atmosphere is between 0.2 and 0.25 except in polar regions (Figure 1d). When the absorbed irradiance is averaged, the global and annual mean shortwave absorptance of the atmosphere is 0.217 . This is significantly larger than the absorptance of 0.196 estimated by Kiehl and Trenberth (1997) and the absorptance of 0.208 estimated by Raschke et al. (2005) from ISCCP-FD data (from 1991 through 1995). As mentioned above, our estimate is based on a two-stream model using cloud properties derived from MODIS and water vapor profile from GEOS 4 while Kiehl and Trenberth (1997) used a standard atmosphere with 49\% low-level, 5\%, middle-level, and 20\% high-level clouds. Aerosols are included in our estimate but excluded in the estimate by Kiehl and Trenberth (1997). The difference is then attributed to the difference in cloud properties (optical thickness, height, droplet size, phase), aerosol properties, and water vapor amount. The net longwave irradiance of the atmosphere $F_{l w}^{a t m}$ is more negative in the tropics than in polar regions (Figure 1b). $F_{l w}^{a t m}$ shows a larger seasonal variation in the northern hemisphere than the southern hemisphere (Figure 1b). Because the larger seasonal variation in the northern hemisphere also appears in the clear-sky net longwave TOA irradiance (Figure 1e), it is likely caused by the seasonal variation in the water vapor amount. The net longwave irradiance $F_{l w}^{a t m}$ over the Antarctic is significantly less negative than $F_{l w}^{a t m}$ over the Arctic because of the lower temperature and water vapor amount over the Antarctica. 
When the net shortwave and longwave atmospheric irradiances are added, $F_{\text {rad }}^{a t m}$ is negative (Figure 1c) because the magnitude of $F_{l w}^{a t m}$ is larger than the magnitude of $F_{s w}^{a t m}$. The value is about $-100 \mathrm{Wm}^{-2}$ for all latitude but $F_{\text {rad }}^{\text {atm }}$ is more negative in the southern hemisphere than in the northern hemisphere. Our estimate of the annual mean atmospheric net irradiance is similar to that given by Zhang and Rossow (1997) from ISCCP FC data, although their estimate does not show the difference between the northern and southern hemispheres.

\subsection{Comparison with Surface Observations}

As mentioned earlier, our estimate of surface irradiance is based on a radiative transfer model. Assumptions made in the estimate process introduce errors in the daily and monthly mean shortwave and longwave surface irradiances. In this section, we compare modeled surface irradiances with observations for the error estimate. Note that the modeled shortwave and longwave TOA irradiances are tuned to agree with CERES irradiances. As a result, the daily global annual mean TOA irradiance agrees with that derived from CERES measurements to within $0.7 \%$ for shortwave and to within $0.2 \%$ for longwave.

We use observations taken at three sites, Manus $\left(2^{\circ} \mathrm{S} 147^{\circ} \mathrm{E}\right.$, tropics $)$, Southern Great Plains $\left(36^{\circ} \mathrm{N} 97^{\circ} \mathrm{W}\right.$, mid-latitude), and Barrow $\left(71^{\circ} \mathrm{N} 156^{\circ} \mathrm{W}\right.$, Arctic). Radiation data at Manus and Southern Great Plains were taken as a part of the Atmospheric Radiation Measurement (ARM, Stokes and Schwartz 1994; Ackerman and Stokes 2003) program run by the Department of Energy. The NOAA/CMDL Solar and Thermal Radiation (STAR) group took radiation data at Barrow, Alaska. Observed shortwave and longwave irradiances taken from March 2000 through Feb. 2003 are averaged to compute monthly mean 
values. Figure 2 shows a comparison of monthly mean shortwave and longwave surface downward irradiances and Table 1 lists the annual mean shortwave and longwave irradiances for the three sites. The modeled annual mean downward shortwave irradiance over three $1^{\circ} \times 1^{\circ}$ grid boxes which contain the three observation sites are $7.8 \%$ greater than the corresponding observations when the differences from the three sites are averaged. Similarly, the mean relative difference of the modeled annual mean downward longwave irradiance over three $1^{\circ} \times 1^{\circ}$ grid boxes containing the three observation sites and corresponding observed irradiances is $1.1 \%$, where modeled irradiances at all three sites are smaller. When modeled shortwave and longwave irradiances are compared with observations at 25 Baseline Surface Radiation Network (BSRN, Ohmura et al. 1988) sites, including above three sites, the mean relative difference is $6.5 \%$ for shortwave and $-3.2 \%$ for longwave and the standard deviation is $5.8 \%$ and $5.1 \%$, respectively. Because the difference from the three sites is within the standard deviation of all BSRN sites, the above three sites are representative for all BSRN sites. Therefore, we use values from the three sites to estimate the errors in the modeled atmospheric irradiance below and Section 3.5. While the reason for the difference of modeled and observed downward surface irradiances especially for shortwave needs to be investigated in future, we treat the difference as the error in the model in this study.

Upward shortwave and longwave irradiances are more problematic because measurements over a small area do not represent a larger area that CERES instruments observe. This is especially true for the Manus site since the most of area within the $1^{\circ} \times 1^{\circ}$ grid box is ocean. The mean relative difference of the modeled and observed upward shortwave 
irradiance of SGP and Barrow sites is 1.7\% (modeled irradiance is greater) and the mean relative difference of the upward longwave irradiances of the two sites is $0.9 \%$ (modeled irradiance is greater). These differences lead to $16.1 \%$ under estimate net shortwave irradiance of the atmosphere and $4.4 \%$ overestimate net longwave irradiance of the atmosphere when the differences over the three sites are averaged. The relative difference of shortwave plus longwave net irradiance of the atmosphere is $-10.8 \%$. Table 1 summarizes the difference between modeled and observed annual mean irradiances at three sites.

\subsection{Comparison with IceSat-derived Cloud Cover}

Because the surface irradiance is computed with MODIS derived cloud properties, it is affected by retrieval errors such as those in cloud fraction, optical thickness, cloud height, droplet size, and phase. A part of error in the surface irradiance shown in the previous section is, therefore, caused by the error in retrieved cloud properties. Even though comparisons of these properties with those derived from more accurate methods are required to fully understand the cause of the error, we expect that the surface irradiance is most sensitive to the cloud fraction among cloud properties. We, therefore, only compare the cloud fraction with that derived from more accurate measurements in this section.

Figure 3 shows the meridional cloud fraction derived from MODIS (Minnis et al. 2003) and from the Geoscience Laser Altimeter System (GLAS) on IceSat (Zwally et al. 2002). The GLAS cloud fraction is derived from a 1064nm laser (medium resolution, GLA09 release 26) and cloud optical thickness is derived from a $532 \mathrm{~nm}$ laser (medium resolution, GLA11 release 24). The maximum optical thickness that GLAS can derive is 5. The monthly mean cloud fraction over northern hemisphere midlatitude and southern hemi- 
sphere midlatitude derived from GLAS is 0.73 and 0.78 , respectively. The corresponding cloud fraction from MODIS derived by the CERES cloud algorithm is 0.58 and 0.79 , respectively. The threshold of cloud detection of the CERES cloud algorithm is 0.3 (Minnis et al. 2003). The fraction of clouds having optical thickness greater than 0.3 derived from GLAS is 0.69 for the northern hemisphere midlatitude and 0.75 for the southern hemisphere midlatitude. If we neglect the sampling time difference between two satellites, the error in the MODIS derived cloud fraction is less than 0.1 in most regions when the cloud fraction from GLAS-derived optical thickness greater than 0.3 is compared.

\subsection{Zonal Mean Cloud Effect}

To understand cloud effects on the energy budget of the atmosphere, we compute the zonal mean cloud radiative effect at the top of the atmosphere and surface, as well as the zonal mean cloud radiative effect to the atmosphere. The cloud radiative effects are computed as the net irradiance under all-sky conditions minus the net irradiance under clear-sky conditions (Ramanathan 1987; Ramanathan et al. 1989). A positive value indicates a warming effect by clouds. To avoid the influence of the water vapor amount and aerosol property differences between clear-sky and all-sky conditions (Li and Trishchenko, 2001), we use computed irradiances with and without clouds for the estimate. In addition, this approach provides the cloud radiative effect for all samples as opposed to the approach using the difference between observed all-sky and clear-sky irradiances. Note that both shortwave and longwave irradiances computed with and without clouds are included in the CRS CERES product. The zonal mean shortwave effects at TOA and the surface are both negative (Figure 4). The zonal mean shortwave effect to the atmosphere is generally positive, which 
indicates that the zonal mean cloud radiative effect at the surface is more negative than that at TOA. A large radiative effect to the atmosphere occurs in midlatitudes in spring and summer in both hemispheres. The zonal mean atmospheric cloud radiative effect is slightly negative (less than $\left.1 \mathrm{Wm}^{-2}\right)$ in the tropics and polar regions $\left(10 \mathrm{Wm}^{-2}\right)$. Note that the negative zonal mean shortwave cloud effect in tropics is within the error estimated in the previous section (the model underestimates by $\approx 10 \mathrm{Wm}^{-2}$ ), if all bias error occurs under cloudy conditions. The zonal mean atmospheric shortwave cloud effect is, therefore, mostly positive. Low-level clouds increase the shortwave absorption in the atmosphere by increasing the photon path length while high-level clouds reduce the transmittance to absorbing water vapor layers at a lower part of the atmosphere. Figure 4 indicates, therefore, increasing absorption by low-level clouds is larger than decreasing absorption by high-level clouds when the effects are weighted by the corresponding probability of cloud occurrence.

The zonal mean cloud longwave effect is shown in Figure 5. When viewed from TOA, clouds reduce the effective temperature by reducing the atmospheric transmittance and increasing emission from the altitude where clouds are located. The effective temperature difference from the clear-sky value decreases as the surface temperature and cloud height decrease so that the zonal mean TOA cloud longwave effect decreases with latitude (Figure 5a). A smaller zonal mean TOA longwave cloud effect near $20 \mathrm{~N}$ and $20 \mathrm{~S}$ is due to a small amount of clouds in these regions. When viewed from the surface, clouds increase the emissivity of the atmosphere and effective temperature. The emissivity difference from a clear-sky value increase as water vapor amount decreases so that the zonal mean cloud radiative effect at the surface increases with latitude (Figure 5b). The drop in the zonal 
mean surface cloud effect over Antarctica is also due to a smaller cloud amount compared to the cloud amount near $60 \mathrm{~S}$. When the zonal mean surface effect is subtracted from the zonal mean TOA effect, the zonal mean atmospheric longwave effect is positive in the tropics and almost linearly decreases with latitude to negative values in polar regions (Figure 5c). This simple linear relation with latitude is caused by the combination of the latitudinal dependence of the difference between the mean cloud top height and water vapor effective emission height determined from the surface and the latitudinal dependence of the cloud fraction (Appendix B).

When zonal mean shortwave and longwave cloud radiative effects are combined, clouds reduce the net irradiance at TOA except in midlatitudes in the winter hemisphere (Figure 6a). The zonal mean surface cloud effect is negative in the tropics and midlatitude and positive in polar regions except in the Arctic summer (Figure 6b). The shortwave effect, therefore, dominates in the cloud radiative effect at TOA and surface in the summer hemisphere. Because the shortwave effect at the TOA and at the surface are both cooling and nearly equal, the longwave effect dominates in the atmosphere (i.e. Figure $6 \mathrm{c}$ closely resembles Figure 5c). Subsequently, when the zonal mean shortwave and longwave effects are combined, a gradient in the meridional atmospheric cloud radiative effect exists, positive in the tropics and negative in polar regions. The meridional gradient persist for all seasons. Because the sign changes between low and high latitudes, the global mean radiative cloud radiative effect to the atmosphere is only $2.2 \mathrm{Wm}^{-2}$ when the zonal mean atmospheric cloud radiative effect is averaged. Although the sign of the cloud radiative effect is different, this small annual and global mean net atmospheric cloud radiative effect 
is consistent with the result by Raschke et al. (2005) who show that the global mean value from ISCCP data is $-1.3 \mathrm{Wm}^{-2}$.

The cloud radiative effect depends on cloud properties. To understand the atmospheric cloud radiative effect dependence on cloud properties, Figure 7 shows the net cloud radiative effect as a function of cloud optical thickness and cloud top pressure. Only single-layer clouds are included in Figure 7 to show the dependence clearly. Cloud optical thickness primarily affects the shortwave irradiance while cloud height primarily affects the longwave irradiance. Note that the atmospheric cloud radiative effect shown in Figure 7 (second row) is the effect in the entire atmospheric column as a function of cloud top height and cloud optical thickness; it is not the vertical profile of the effect. Figure 7 shows that the atmospheric cooling effect in polar regions is caused by low-level clouds, which occur most frequently in polar regions (Figure 7 bottom row). The atmospheric effect of high-level clouds is warming for all regions (Figure 7). The warming effect is larger in the tropics than in polar regions because the frequency of occurrence of thick high-level clouds is larger and the mean cloud top height of high-level clouds is higher in the tropics.

In addition to radiation, clouds also expect to affect the enthalpy flux (i.e. sensible heat and latent heat fluxes) at the surface. Because our goal is to estimate the cloud effect on meridional energy transport by the atmosphere, we need to quantify the cloud effect on the surface enthalpy flux. We use the surface enthalpy flux from the NCEP reanalysis (Kalnay et al. 1996) for the estimate. We assume that the enthalpy flux is proportional to the net surface irradiance so that the cloud effect on the enthalpy flux $F_{H}-F_{H, c l r}$ is

$$
F_{H}-F_{H, c l r}=F_{H}\left(1-F_{\text {rad,clr }}^{s f c} / F_{\text {rad }}^{s f c}\right),
$$


where $F_{H}$ is the enthalpy flux under all-sky conditions, $F_{r a d}^{s f c}$ is the net irradiance at the surface and the subscript $c l r$ indicates the clear-sky condition. The cloud effect $F_{c l d}^{s f c}$, combined the radiative and surface enthalpy fluxes, is, therefore,

$$
F_{c l d}^{s f c}=F^{s f c}-F_{c l r}^{s f c}=\left(F_{r a d}^{s f c}+F_{H}^{s f c}\right)\left(F_{r a d}^{s f c}-F_{r a d, c l r}^{s f c}\right) / F_{r a d}^{s f c} .
$$

With this assumption, the total cloud effect is the cloud radiative effect multiplied by the ratio of the sum of the net irradiance and enthalpy flux to the net irradiance.

The parameterization of surface enthalpy flux suggests that the flux is a function of wind speed and local gradient between sea surface and atmosphere (Washington and Parkinson 1986, p122, Fairall et al. 1996). We need to test, therefore, if there is any relation between the net surface irradiance and surface enthalpy flux using observations. For this purpose, we used the surface enthalpy flux from Hamburg Ocean Atmosphere parameters and fluxes from Satellite monthly data (HOAPS-3, 0.5 global grid, Grassl et al. 2000). Figure 8 shows the surface enthalpy flux anomalies divided by the monthly mean value as a function of the net surface irradiance anomalies divided by the monthly mean value from March 2000 between $20^{\circ} \mathrm{N}$ and $20^{\circ} \mathrm{S}$. The anomalies are defined as the deviation of the zonal mean values from the monthly mean value over the four-year period from March 2000 through Dec. 2004. Although, Figure 8 indicates that the surface enthalpy flux change is positively correlated with the surface net irradiance change, the correlation coefficient is 0.16 . If ocean surface property changes are caused by radiation and surface flux is balanced by the surface net irradiance, the surface enthalpy flux is likely to correlate with the surface net irradiance. A weak correlation shown in Figure 8 indicates, however, that the surface enthalpy flux anomalies are not predominately driven by the net surface 
irradiance anomalies over tropical oceans in a monthly time scale. We, therefore, consider that the cloud effect on the surface enthalpy flux estimated with (5) is the maximum cloud effect on the surface enthalpy flux. The minimum effect is simply no cloud effect on the surface enthalpy flux. The uncertainty envelope of the atmospheric cloud effect is then given with and without the assumption (5) on the surface enthalpy flux. The uncertainty in the cloud effect on the surface enthalpy flux is large in the tropics where the surface enthalpy flux is large. When the surface enthalpy flux is small, such as in midlatitudes and polar regions, the uncertainty envelope is also small.

When the cloud effect on the surface enthalpy flux is included with the assumption that the cloud effect on the enthalpy flux is proportional to the net surface irradiance, the positive effect in the tropical atmosphere is almost eliminated (Figure 9). Therefore, the uncertainty in the cloud effect on the surface enthalpy flux is too large to determine the atmospheric cloud effect observationally over tropics. However, the meridional gradient of atmospheric cloud effects between mid-latitude and polar regions remains because of a stronger cooling caused by clouds in polar regions and a smaller net enthalpy flux at the surface.

Our zonal mean atmospheric cloud radiative effect in the tropics is smaller than that estimated by Randall et al. (1989, Figure 20) who ran a general circulation model with and without clouds over oceans to estimate zonal mean atmospheric cloud radiative effect. Their result indicates that the cloud radiative effect is to intensify Hadley circulation and tropical easterlies. These are caused by a larger tropical boundary layer wind speed, stronger surface evaporation, and a larger water vapor amount in the atmosphere. In their 
study, therefore, the cloud effect on the surface enthalpy flux is to increase the flux, further warm the atmosphere and cool the surface instead of offsetting the cloud radiative effect in the tropics. This is opposite in effect compared with the cloud effect estimated with our assumption. Therefore, their zonal mean atmospheric cloud effect is larger than our estimate in the tropics. This suggests that the cloud effect on the surface enthalpy flux by (5) is too large and the gradient of zonal mean cloud effect between the tropics and midlatitude might exist. Our zonal mean atmospheric cloud radiative effect over midlatitudes and polar regions is, however, similar to that estimated by Randall et al. Our result of the meridional gradient of cloud effect in mid-latitude and polar regions is, therefore, consistent with the result by Randall et al. (1989) that clouds intensify subtropical westerly jets because the meridional gradient of the atmospheric cloud effect between midlatitude and polar regions can enhance the vertical shear of geostrophic winds through the thermal wind relation (e.g. Holton p75).

\subsection{Meridional Gradient Error Estimate}

If we take the mean net irradiance of the atmosphere from three sites used for the comparison, the relative difference of $-10.8 \%$ estimated in Section 3.2 corresponds to a $9.5 \mathrm{Wm}^{-2}$ bias error. As shown in Table 1, the net irradiance of the atmosphere over the SGP site is biased high by $3.1 \mathrm{Wm}^{-2}$ and that over the Barrow site is biased low by $9.7 \mathrm{Wm}^{-2}$. If we assume that all the error occurs in cloudy conditions and the error in clear-sky irradiances are negligible, the bias error in the zonal mean net atmospheric radiative cloud effect is $-9.5 \mathrm{Wm}^{-2}$ and the uncertainty in the gradient between midlatitude and polar regions is 12.8 $\mathrm{Wm}^{-2}$. This error estimate in the zonal mean cloud effect is the upper limit because 
the error in the shortwave daily mean irradiance is partly due to underestimate water vapor amount in the atmosphere at large solar zenith angle in low latitudes, which affects both all-sky and clear-sky downward shortwave irradiances. A comparison with IceSat derived cloud fraction shows that the MODIS-derived cloud fraction is biased low at northern hemisphere midlatitude and biased high at $70^{\circ} \mathrm{N}$. Because the atmospheric cloud effect in polar regions is more cooling than that in midlatitudes, the cloud fraction error at two sites is consistent with the error estimate of the meridional gradient of cloud effect. Note that the error estimate derived from a comparison with surface observation includes the effect of errors in cloud retrieval since modeled surface irradiances were computed with MODIS-derived cloud properties.

Zhang and Rossow (1997) estimated that the uncertainty in the zonal mean surface enthalpy flux is at least $20 \mathrm{Wm}^{-2}$. This corresponds to about $13 \%$ of the net surface irradiance over tropical oceans. This leads to a $13 \%$ uncertainty in the surface cloud effect by (6), which gives about a $5 \mathrm{Wm}^{-2}$ uncertainty in both the zonal mean surface and atmospheric cloud effect. Because of a smaller surface enthalpy flux in midlatitude and polar regions than in tropics, we expect that the uncertainty in the zonal mean atmospheric cloud effect due to the uncertainty in the surface enthalpy flux is smaller than $5 \mathrm{Wm}^{-2}$ in midlatitude and polar regions. Therefore, the gradient of the cloud effect between midlatitudes and polar regions shown in Figure 9 is significant even when the modeling error and uncertainty in the surface enthalpy flux are considered. More importantly, the meridional gradient of cloud effect is physically plausible as described in section 3.2. We therefore conclude that the meridional gradient of cloud effect in midlatitude and polar regions is significant and 
subsequently estimate the cloud effect on meridional energy transport in section 4 .

\section{Discussion}

Clouds present in polar regions cool the atmosphere more than those in mid latitude and tropics cool their residing atmosphere. The meridional gradient of the atmospheric cloud effect enhances the temperature gradient in the atmosphere from that found under clearsky conditions. Because mean zonal available potential energy is generated by heating warm air at low latitudes and cooling cold air at high latitudes (Lorenz, 1955; Peixoto and Oort 1992, p377), this indicates that clouds increase the rate of generation of mean zonal available potential energy in the atmosphere (Stuhlmann and Smith 1988).

Energy transport to polar regions by dynamics can compensate for cooling by clouds if zonal mean available potential energy is converted to kinetic energy. If energy transport by dynamics in the atmosphere does not compensate cooling by clouds, the atmosphere is simply colder than the atmosphere with no clouds and the meridional temperature gradient in the atmosphere can intensify with time without changing the TOA net irradiance significantly. Because clouds alter the net TOA irradiance as shown in Figure 6, it is postulated that clouds affect the rate of meridional energy transport (e.g. Zhang and Rossow 1997; Moore and Vonder Haar 2001; Weaver 2003). In this paper, we therefore, estimate the rate of energy transport by the atmosphere equivalent to the zonal mean cloud effect using a CERES data set. We then examine, based on the zonal mean atmospheric effect by cloud type, whether or not dynamics can indeed utilize the meridional gradient of the cloud effect in transporting the energy poleward.

Before a detailed analysis, the significance of the meridional gradient of the zonal 
mean cloud effect can be understood from a simple scale analysis. If we take

$$
\frac{\Delta F_{c l d}^{a t m}}{L c_{p} \rho h}
$$

as the meridional temperature gradient generated by clouds per unit time, where $\Delta F_{c l d}^{a t m}$ is the difference in the cloud effect separated by the horizontal length $L, \rho$ is the density of air, $h$ is the depth of the atmosphere, and $c_{p}$ is the specific heat capacity of air at constant pressure, and use $\Delta F_{\text {rad }}=10 \mathrm{Wm}^{-2}$ over $1000 \mathrm{~km},(7)$ is approximately $1 \times 10^{-12} \mathrm{Ks}^{-1} \mathrm{~m}^{-1}$. Taking a typical meridional temperature gradient of $0.01 \mathrm{Kkm}^{-1}$, we find that the zonal mean atmospheric cloud effect is equivalent to about $5 \%$ of the temperature gradient if clouds persist 4 to 5 days. It is, therefore, not negligible, although the meridional gradient of cloud effect is a small fraction of the rate of generation of mean zonal available potential energy.

The zonal mean energy in the atmosphere changes with time because of the meridional energy flux gradient in the atmosphere, TOA zonally averaged net irradiance $F_{\text {rad }}^{\text {atm }}$, and enthalpy flux from the surface,

$$
\frac{\partial E}{\partial t}=-\frac{h}{R \cos \theta} \frac{\partial \cos \theta F_{\theta}}{\partial \theta}+F_{\text {rad }}^{a t m}+F_{H}
$$

where $E$ is the zonal mean energy in a vertical atmospheric column, $\theta$ is the latitude, $F_{\theta}$ is the vertically averaged meridional component of the energy flux, $R$ is the radius of the earth, and $h$ is the height of the atmosphere. In a steady state condition, the radiative and enthalpy fluxes are balanced with meridional energy flux divergence in the atmosphere

$$
\frac{h}{R \cos \theta} \frac{\partial \cos \theta F_{\theta}}{\partial \theta}=F_{r a d}^{a t m}+F_{H}
$$


When $F_{\text {rad }}^{a t m}+F_{H}$ is integrated along latitude, we obtain the rate of energy crossing a vertical latitudinal plane in the atmosphere (e.g. Zhang and Rossow, 1997; Trenberth and Caron, 2001; Trenberth and Stepaniak 2003). As discussed in the previous section, we assume that the zonal mean cloud effect on $F_{\text {rad }}^{a t m}+F_{H}$ can be separated from those under clear-sky conditions such that $F_{\text {rad }}^{a t m}+F_{H}=F_{c l d}^{a t m}+F_{c l r}^{a t m}$ where $F_{c l d}^{a t m}=\left(F_{\text {rad }}^{a t m}+F_{H}\right)_{c l d}$ and $F_{c l r}^{a t m}=\left(F_{\text {rad }}^{a t m}+F_{H}\right)_{c l r}$. We then estimate the zonal mean cloud effect on the vertical mean meridional energy flux $F_{c}$ by setting

$$
F_{c l d}^{a t m}=-\frac{h}{R \cos \theta} \frac{\partial \cos \theta F_{c}}{\partial \theta}
$$

Then, (8) is

$$
\frac{\partial E}{\partial t}=-\frac{h}{R \cos \theta} \frac{\partial \cos \theta\left(F_{\theta}+F_{c}\right)}{\partial \theta}+F_{c l r}^{a t m}
$$

where $-\frac{h}{R \cos \theta} \frac{\partial \cos \theta F_{c}}{\partial \theta}$ is the meridional convergence of the energy flux that is equivalent to the zonal mean cloud effect. Equation 11 can be considered as the energy equation for a clear-sky atmospheric column. Under clear-sky conditions, $\frac{\partial E}{\partial t}$ is not zero because the temperature profile needs to adjust from that under all-sky conditions. The global mean rate of the energy change in (11) is negative because the global mean atmospheric cloud radiative effect is slightly positive $\left(\approx 2 \mathrm{Wm}^{-2}\right)$. To reach a steady state, therefore, the atmosphere needs to adjust the temperature profile corresponding to the meridional clear-sky net irradiance distribution.

To obtain $F_{c}$, we substitute (9) in (11),

$$
-\frac{h}{R \cos \theta} \frac{\partial \cos \theta F_{c}}{\partial \theta}=F_{c l d}^{a t m}+\frac{\partial E}{\partial t} .
$$

Here, we are not interested in the meridional profile after the system reaches a steady state under clear-sky conditions. We are interested in estimating the energy transport 
that is equivalent to the zonal mean cloud effect under all-sky conditions. Therefore, (12) is integrated over latitude and longitude by setting that $-\frac{\partial E}{\partial t}$ equal to the seasonal global mean of $F_{c l d}^{a t m}$ for all latitudes so that $F_{c}$ at poles is zero. The resulting $2 \pi R h F_{c} \cos \theta$ is the rate of the energy crossing a vertical latitudinal plane in the atmosphere that is equivalent to the zonal mean cloud effect. The underlying assumption is that the local rate of the energy change is uniform when clouds are removed.

Figure 10 shows the rate of meridional energy transport in the atmosphere $2 \pi R h F_{c} \cos \theta$ separated by seasons. Positive values indicate northward transport and negative values indicate southward transport. Two lines that provide the uncertainty envelope are shown in each plot. The solid line is the total cloud effect integrated along latitude and the dash-dot line considers only the radiative effect. As the effect of radiation on the surface enthalpy flux increases, $2 \pi R h F_{c} \cos \theta$ approaches to the line that includes the surface enthalpy change in the cloud effect. The energy transport has a maximum (minimum) in the northern hemisphere (southern hemisphere) midlatitude and it is mostly positive (negative) in the midlatitude to polar regions, especially in the fall and winter hemisphere. This estimate neglects dynamical feedbacks such as the enthalpy flux change due to wind speed change suggested by Randall et al. (1989). When the cloud indirect effect on the surface enthalpy flux is included, however, the study by Randall et al. (1989) suggests that the cloud effect on the meridional enthalpy transport might be larger in the tropics. These two estimates (dash-dot and solid lines in Figure 10), therefore, can be considered as an envelope of the rate of the meridional atmospheric energy transport equivalent to the zonal mean direct cloud effect. This 
result indicates that the meridional gradient of cloud effect increases the rate of poleward energy transport from midlatitude to polar regions by dynamics in the atmosphere.

As mentioned earlier, the atmospheric temperature under a clear-sky condition can be different from that under the all sky condition. A clear-sky atmosphere in midlatitude and polar regions can be warmer so that the net atmospheric irradiance under all-sky conditions may not be much different from the clear-sky value. This is unlikely for two reasons. First, a clear-sky atmosphere needs to be warmer by more than $10 \mathrm{~K}$ to compensate the cloud effect of about $30 \mathrm{Wm}^{-2}$ regionally. Second, the vertical distribution of cloud radiative effect works favorably for dynamics to transport energy poleward for the following reason. In a case where clouds move with winds, we apply the thermodynamic energy equation to a column moving poleward

$$
\frac{D E}{D t}=V \frac{D p}{D t}+F_{r a d}
$$

where $V$ is the volume of the column. When we neglect the pressure change with time and integrate this over time we obtain the energy transported by the column

$$
\left[E\left(t_{1}\right)-E\left(t_{0}\right)\right]=\frac{1}{v} \int_{y_{0}}^{y_{1}} F_{c l d}(y)+F_{c l r}(y) d y
$$

where $v$ is the meridional velocity of the column and the column is at $y_{0}$ at $t=t_{0}$ and at $y_{1}$ at $t=t_{1}$. The column is heated or cooled by radiation $F_{c l d}+F_{c l r}$ at $y$. If clouds cool the column when they move poleward with the column, $E\left(t_{1}\right)$ is lower than that in a column without clouds so that the cloud reduces the energy transport. Therefore, the effect of clouds on the energy transport depends on the movement of clouds relative to wind. Figure 7 suggests that, however, the atmospheric cooling effect is caused by low-level clouds. Low-level clouds tend to form locally and remain relatively stationary. Because a 
stronger cooling in polar regions is caused by low-level clouds, which subsequently causes the meridional temperature gradient, the rate of meridional energy transport to polar regions increases. High- and middle-level clouds, which tend to be advected by wind, have a warming effect to the atmosphere (Figure 7). When high- and middle-level clouds are advected poleward, the covariance of the column integrated temperature deviation due to clouds and the meridional component of velocity is positive. Because mean zonal available potential energy is converted to eddy available potential energy through poleward transport of warm air (Lorenz, 1955; Peixoto and Oort 1992, p377), this indicates that the rate of conversion of mean to eddy available potential energy is also increased when mid and high-level clouds are advected. Therefore, the meridional and vertical gradients of cloud effect increase the rate of generation of mean zonal available potential energy, rate of conversion of mean to eddy available potential energy, and rate of meridional energy transport from midlatitude to polar region through the atmosphere.

\section{Conclusions}

We estimated the zonal mean radiative cloud effect to the atmosphere using three years of CERES data. Although it is mostly positive for all four seasons, the zonal mean shortwave atmospheric cloud effect is small. A large effect occurs near midlatitudes in spring and summer presumably due to a large cloud fraction. Clouds, therefore, increase the shortwave absorption in the atmosphere. The net zonal mean atmospheric cloud radiative effect is, however, dominated by the longwave effect. The zonal mean longwave effect is a warming in the tropics and decreases approximately linearly with latitude to a cooling effect in polar regions. The meridional dependent atmospheric cloud radiative effect is a result 
of decreasing the TOA cloud effect and increasing the surface cloud effect with latitude. This meridional dependence of the cloud effects is caused by the latitudinal difference of the mean cloud top height and water vapor effective emission height determined from the surface and the latitudinal variation in the cloud fraction.

We consider the upper limit of the cloud effect of the surface enthalpy flux by the assumption that the cloud effect of the surface enthalpy flux is proportional to the net irradiance at the surface. The uncertainty envelope of the atmospheric cloud effect is between the upper limit and lower limit that is simply given by no cloud effect on the surface enthalpy flux. While the uncertainty in the cloud effect on the surface enthalpy flux is large in the tropics, the meridional gradient between midlatitude and polar regions exists even when uncertainties in the cloud effect on the surface enthalpy flux and in the modeled irradiances are taken into account.

The atmospheric cooling effect of clouds in midlatitude and polar regions is caused by low-level clouds. Frequently occurring low-level clouds and their stronger cooling effect in polar regions lead to the meridional gradient of cloud effect between midlatitude and polar regions. The meridional gradient of cloud effect increases the rate of generation of mean zonal available potential energy. Because the cooling effect over polar regions is caused by relatively stationary low-level clouds, the meridional gradient of cloud effect increases the rate of meridional energy transport. Middle- and high-level clouds, which tend to be advected by winds have warming effects to the atmosphere. This leads to increase the rate of conversion of mean to eddy available potential energy. Clouds in polar regions then warm the surface except in the Arctic in summer. 
Because clouds form as a consequence of dynamics, these results suggest a possible feedback process (e.g. Weaver 2003) among cloud type, meridional energy transport, and surface temperature in polar regions. If we consider that about $50 \%$ of the energy emitted to space by polar regions is provided from midlatitudes (Kato et al. 2006), understanding the link between energy transport and the zonal mean cloud effect is as equally important as understanding local cloud feedback processes in polar regions.

\section{Acknowledgments}

We thank Drs. Bruce Wielicki, Dennis Hartmann, Tony Slingo, and Norman Loeb for useful discussions, Dr. Christopher Weaver for useful comments, and the NOAA/CMDL Solar and Thermal Radiation (STAR) group for providing surface radiation measurements. NCEP Reanalysis data provided by the NOAA/OAR/advection PSD, Boulder, Colorado, USA, from their Web site at

http://www.cdc.noaa.gov/. HOAPS data are obtained from their Web site at http://www.hoaps.zmaw.de/.

ARM data were made available through the U.S. Department of Energy as part of the Atmospheric Radiation Measurement Program. The CERES data were obtained from the NASA Langley Atmospheric Science Data Center. The work was supported by a grant from the CERES project (NNL04AA26G) and a NASA grant (NNG04GL94G). 


\section{Appendix A: Daily Mean Irradiance Estimate}

To convert instantaneous irradiances to a daily value, we need to obtain the TOA albedo, transmission, and surface albedo as a function of solar zenith angle. We sort and average instantaneous TOA albedos estimated from CERES radiance as a function of solar zenith angle and scene type using data taken from the TRMM satellite from January 1998 through August 1998 and March 2000. Note that the effect of a spherical earth that leads to a nonnegligible TOA shortwave irradiance over regions where the solar zenith angle is greater than $90^{\circ}$ is included based on Kato and Loeb (2003). Similarly, we sort and average transmissions and surface albedos as a function of solar zenith angle and scene type using one-year of Terra CRS from March 2000 through February 2001. The increment of the solar zenith angle bin is $10^{\circ}$ for the TOA albedo and $5^{\circ}$ for the surface transmission and albedo. The number of scene types that contain no snow and sea ice is 590 (Loeb et al. 2003). The number of snow and sea ice scenes is 60 (Kato and Loeb 2005).

The instantaneous irradiance $F_{i, s w}^{T O A}$ is scaled by the ratio of the daily mean TOA albedo $A^{T O A}(x)$ to the instantaneous TOA albedo $A_{i}^{T O A}\left(\theta_{0}, x\right)$,

$$
F_{s w}^{T O A}(x)=F_{i, s w}^{T O A}\left(\theta_{0}, x\right) \frac{A^{T O A}(x)}{A_{i}^{T O A}\left(\theta_{0}, x\right)}
$$

where $F_{s w}^{T O A}$ is the daily mean TOA irradiances, $\theta_{0}$ is the solar zenith angle, and $x$ is the scene type over a CERES footprint that is estimated from MODIS radiances. The diurnal change of solar zenith angle over the course of a day for the location of the radiance measurement is used to compute $A^{T O A}(x)$. Similarly, the daily mean downward and upward shortwave surface irradiances are computed by

$$
F_{s w, d n}^{s f c}(x)=F_{i, d n}^{s f c}\left(\theta_{0}, x\right) \frac{T(x)}{T_{i}\left(\theta_{0}, x\right)},
$$


and

$$
F_{s w, u p}^{s f c}(x)=F_{i, u p}^{s f c}\left(\theta_{0}, x\right) \frac{A(x)}{A_{i}\left(\theta_{0}, x\right)}
$$

where $T(x)$ and $A(x)$ are transmittance and surface albedo averaged over the course of a day for the scene type $x$, and $T_{i}\left(\theta_{0}, x\right)$ and $A_{i}\left(\theta_{0}, x\right)$ are the instantaneous transmittance and surface albedo at the CERES overpass time, respectively.

\section{Appendix B: Zonal Mean Atmospheric Cloud Radiative Effect}

Figure 6 shows that the zonal mean atmospheric cloud radiative effect, which is dominated by the longwave effect, changes almost linearly with latitude. In addition, the meridional gradient is larger than the seasonal variations. In this appendix, we explain the reason for this simple latitudinal dependence of the zonal mean atmospheric cloud radiative effect. Because the atmospheric cloud radiative effect is dominated by longwave, we only consider the longwave effect here. We utilize a plane parallel atmosphere with the temperature $T_{a}$, and emissivity $\epsilon$. The temperature of the underlying surface is $T_{s}$ and the emissivity is

assumed to be unity. The top-of-atmosphere longwave net irradiance $F_{l w}^{T O A}$ and surface longwave net irradiance $F_{l w}^{s f c}$ is

$$
F_{l w}^{T O A}=-\left[(1-\epsilon) \sigma T_{s}^{4}+\epsilon \sigma T_{a}^{4}\right]
$$

and

$$
F_{l w}^{s f c}=\epsilon \sigma T_{a}^{4}-\sigma T_{s}^{4} .
$$

If we let $T_{a}=T_{s}+\Delta T$, then

$$
F_{l w}^{T O A} \approx-\sigma T_{s}^{4}\left(1+\frac{4 \epsilon \Delta T}{T_{s}}\right)
$$


and

$$
F_{l w}^{s f c} \approx-\sigma T_{s}^{4}\left[1-\epsilon-\frac{4 \epsilon \Delta T}{T_{s}}\right]
$$

The longwave cloud radiative effect at the top of the atmosphere $F_{l w}^{T O A}-F_{l w, c l r}^{T O A}$ and the surface $F_{l w}^{s f c}-F_{l w, c l r}^{s f c}$ is

$$
F_{l w}^{T O A}-F_{l w, c l r}^{T O A}=-4 \sigma T_{s}^{3}\left(\epsilon \Delta T-\epsilon_{c l r} \Delta T_{c l r}\right) f_{c}
$$

and

$$
F_{l w}^{s f c}-F_{l w, c l r}^{s f c}=\sigma T_{s}^{4}\left[\epsilon\left(1+4 \frac{\Delta T}{T_{s}}\right)-\epsilon_{c l r}\left(1+4 \frac{\Delta T_{c l r}}{T_{s}}\right)\right] f_{c}
$$

where the subscript $c l r$ indicates the clear condition and $f_{c}$ indicates cloud fraction. Because clouds reduce effective temperature when viewed from TOA, $\epsilon \Delta T-\epsilon_{c l r} \Delta T_{c l r}$ is negative. When viewed from the surface, clouds increase the emissivity of the atmosphere and effective temperature, the right side of (a9) is positive.

If we assume that the difference between the effective temperature and surface temperature $\Delta T$ is

$$
\begin{gathered}
\Delta T=\frac{d T}{d z} z_{t o p}, \\
\Delta T_{c l r}=\frac{d T}{d z} z_{t o p, w v},
\end{gathered}
$$

and the emissivity of clear-sky atmosphere is

$$
\epsilon_{c l r}=1-e^{-\tau_{w v}}
$$

where $z$ is the altitude, $z_{t o p}$ is the cloud top height, $z_{t o p, w v}$ is the effective height of water vapor that gives effective temperature of clear-sky when viewed from TOA, and $\tau_{w v}$ is the 
optical thickness of water vapor. We also assume that the emissivity of clouds is unity, $\epsilon=1$. In addition, we assume

$$
\begin{gathered}
\Delta T=\frac{d T}{d z} z_{b a s e} \\
\Delta T_{c l r}=\frac{d T}{d z} z_{b a s e, w v}
\end{gathered}
$$

and

$$
\epsilon_{c l r}=1-e^{-\tau_{w v}},
$$

where $z_{\text {base }}$ is the cloud base height and $z_{\text {base,wv }}$ is the effective height of water vapor that gives effective temperature of clear-sky when viewed from the surface.

Substituting (a10) through (a15) into (a8) and (a9) and assuming that the column water vapor amount is sufficient to give $\tau_{w v} \gg 1$, we then obtain

$$
F_{l w}^{T O A}-F_{l w, c l r}^{T O A}=-4 \sigma T_{s}^{3} \frac{d T}{d z}\left(z_{t o p}-z_{t o p, w v}\right) f_{c}
$$

and

$$
F_{l w}^{s f c}-F_{l w, c l r}^{s f c}=\sigma T_{s}^{3} \frac{d T}{d z}\left(z_{b a s e}-z_{b a s e, w v}\right) f_{c} .
$$

Figure 5 shows that the meridional gradient of atmospheric cloud radiative effect in tropics and midlatitudes is caused by both TOA and surface effects and that over polar regions is predominately caused by the TOA effect. Figures a1 and 3 indicate that $z_{t o p}$ decreases with latitude between $20 \mathrm{~N}$ and $20 \mathrm{~S}$ probably more than $z_{t o p, w v}$ does. The cloud fraction $f_{c}$ also decreases with latitude between $20 \mathrm{~N}$ and $20 \mathrm{~S}$. Therefore, the zonal mean TOA cloud radiative effect decreases with latitude in this region. Because the column water vapor amount decreases with latitude, $z_{b a s e, w v}$ increases while $z_{b a s e}$ is relatively constant with latitude. As a consequence, the zonal mean cloud radiative effect at the surface 
increases with latitude. Figure a1 also indicates that the cloud height decreases with latitude in polar regions. Therefore the zonal mean TOA cloud radiative effect decreases with latitude in polar regions. Because the zonal mean atmospheric cloud radiative effect is (a17) subtracted from (a16),

$$
\left(F_{l w}^{T O A}-F_{l w, c l r}^{T O A}\right)-\left(F_{l w}^{s f c}-F_{l w, c l r}^{s f c}\right)=-4 \sigma T_{s}^{3} \frac{d T}{d z}\left[\left(z_{t o p}-z_{\text {top }, w v}\right)+\left(z_{\text {base }}-z_{\text {base }, w v}\right)\right] f_{c} . \quad(a 18)
$$

The zonal mean atmospheric cloud radiative effect is, therefore, a function of the difference between the mean cloud height and water vapor effective emission height multiplied by the cloud fraction. In the tropics, $z_{t o p}$ is higher than $z_{t o p, w v}$ and $z_{b a s e}$ is nearly equal to $z_{b a s e, w v}$. Therefore, the zonal mean atmospheric cloud radiative effect is positive in the tropics. In polar regions, the difference between $z_{\text {top }}$ and $z_{t o p, w v}$ is small while $z_{\text {base }}$ is less than $z_{b a s e, w v}$ Therefore, the zonal mean atmospheric cloud radiative effect is negative in polar regions. If we assume the difference between $z_{\text {base }}$ and $z_{t o p, w v}$ is small compared with the difference between $z_{\text {top }}$ and $z_{b a s e, w v}$, then

$$
\left(F_{l w}^{T O A}-F_{l w, c l r}^{T O A}\right)-\left(F_{l w}^{s f c}-F_{l w, c l r}^{s f c}\right)=-4 \sigma T_{s}^{3} \frac{d T}{d z}\left(z_{t o p}-z_{b a s e, w v}\right) f_{c},
$$

which indicates that the zonal mean atmospheric cloud radiative effect is, to a first order approximation, a function of difference between the mean cloud top height and water vapor effective emission height determined from the surface longwave irradiance multiplied by the cloud fraction. While this does not explain the reason for a simple linear relation with latitude, it tells that the sign of the zonal mean atmospheric cloud radiative effect changes going from the tropics to polar regions. 


\section{References}

Ackerman, T. P., and G. M. Stokes, 2003: The atmospheric Radiation Measurement program, Phys. Today, 56, 38-45.

Bloom, S. A., and coauthors, 2005: Documentation and validation of the Goddard Earth Observing System (GEOS) data assimilation system version-4, Technical Report Series on Global Modeling and Data Assimilation, 104606, 26.

Charlock, T. P, F. G. Rose, D. A. Rutan, Z. Jin, and S. Kato, 2006: The global surface and atmosphere radiation budget: An assessment of accuracy with 5 years of calculations and observations, Proceedings of 12th Conference on Atmospheric Radiation, 10-14, July, Madison Wisconsin.

Collins, W. D., P. J. Rasch, B. E. Eaton, B. V. Khattatov, J.-F. Lamarque, and C. S. Zender, 2001: Simulating aerosols using a chemical transport model with assimilation of satellite aerosol retrievals: Methodology for INDOEX, J. Geophys. Res., 106, 7313-2025.

Fairall, C. W., E. F. Bradley, D. P. Rogers, J. B. Edson, G. S. Young, 1996: Bulk parameterization of air-sea fluxes for Tropical Ocean-Global Atmosphere Coupled-Ocean Atmosphere Response Experiment., J. Geophys. Res., 101, 3747-3764.

Fu, Q., and K.-N. Liou, 1993: Parameterization of the radiative properties of cirrus clouds, J. Atmos. Sci., 50, 2008-2025.

Grassl H., V. Jost, R. Kumar, J. Schulz, P. Bauer, P. Schluessel, 2000: The Hamburg OceanAtmosphere Parameteres and Fluxes from Satellite Data (HOAPS): A Climatological Atlas of Satellite-Derived Air-Sea-Interaction Parameters over the Oceans., Report No. 312, ISSN 0937-1060, Max Planck Institute for Meteorology, Hamburg. 
Holton, J. R., 1992: An introduction to Dynamical Meteorology, 3ed ed., Academic, New York, 511pp.

Jin, Z, and K. Stamnes, 1994: Radiative transfer in nonuniformly reflecting layered media: Atmosphere-ocean system, Appl. Opt., 33, 431-442.

Kalnay et al.,The NCEP/NCAR 40-year reanalysis project, 1996: Bull. Amer. Meteor. Soc., 77, 437-470.

Kato, S., N. G. Loeb, P. Minnis, J. A. Francis, T. P. Charlock, D. A. Rutan, E. E. Clothiaux, S. Sun-Mack, 2006: Seasonal and Interannual Variations of Top-of-Atmosphere Irradiance and Cloud Cover over Polar Regions Derived from the CERES Data Set, Geophys. Res. Lett., 33, L19804, doi:10.1029/2006GL026685.

Kato, S., and F. G. Rose, and T. P. Charlock, 2005: Computation of Domain-averaged Irradiance Using Satellite-derived Cloud Properties, J. Atmos. Oceanic Technol., 22, 146164.

Kato, S., and N. G. Loeb, 2005: Top-of-atmosphere shortwave broadband observed radiance and estimated irradiance over polar regions from Clouds and the Earth's Radiant Energy System (CERES) instruments on Terra, J. Geophys. Res., 110, D7, D07202 10.1029/2004JD005308.

Kato, S., and N. G. Loeb, 2003: Twilight irradiance reflected by the earth estimated from Clouds and the Earth's Radiant Energy System (CERES) measurements, J. Climate, 16, 2646-2650.

Kiehl, J. T. and K. E. Trenberth, 1997: Bull. Amer. Meteor. Soc., 78, 197-208. 
Li, Z., A. Trishchenko, 2001: Quantifying uncertainties in determining SW cloud radiative forcing and cloud absorption due to variability in atmospheric conditions, J. Atmos. Sci., 58, 376-389.

Loeb, N. G., S. Kato, K. Loukachine, and N. M. Smith, 2006: Angular Distribution Models for Top-of-Atmosphere Radiative Flux Estimation from the Clouds and the Earth's Radiant Energy System Instrument on the Terra Satellite. Part II: Validation, J. Atmos. Oceanic Technol., 24, 564-584.

Loeb, N. G., S. Kato, K. Loukachine, and N. M. Smith, 2005: Angular Distribution Models for Top-of-Atmosphere Radiative Flux Estimation from the Clouds and the Earth's Radiant Energy System Instrument on the Terra Satellite. Part I: Methodology, J. Atmos. Oceanic Technol, 22, 338-351.

Loeb, N. G., N.-M. Smith, S. Kato, W. F. Miller, S. K. Gupta, P. Minnis, and B. A. Wielicki, 2003: Angular distribution models for top-of atmosphere radiative flux estimation from the Clouds and the Earth's Radiant Energy System instrument on the Tropical Rainfall Measuring Mission Satellite, J. Appl. Meteor., 42, 240-265.

Lorenz, E. N, 1955: Available potential energy and the maintenance of the general circulation, Tellus, 7, 157-167

Minnis, P., D. F. Young, S. Sun-Mack, P. W. Heck, D. R. Doelling, and Q. Trepte, 2003: CERES Cloud Property Retrievals from Imagers on TRMM, Terra, and Aqua, Proc. SPIE 10th International Symposium on Remote Sensing, Conference on Remote Sensing of Clouds and the Atmosphere VII, Barcelona, Spain, September 8-12, 37-48. 
Moore, R. W., and T. H. Vonder Haar, 2001: Interannual variability of cloud forcing and meridional energy transport for the northern hemisphere winter from 1984 to 1990, J. Climate, 14, 3643-3654.

Ohmura A., and co-authors, 1998: Baseline Surface Radiation Network (BSRN/WCRP): New precision radiometery for climate change research, Bull. Amer. Meteor. Soc., 79, $2115-2136$.

Peixoto, J. P, and A. H. Oort, 1992: Physics of climate, American Institute of Physics, pp520 Ramanathan, V., R. D. Cess, E. F. Harrison, P. Minnis, R. B. Barkstrom, E. Ahmad, and D. Hartmann, 1989: Cloud-radiative forcing and climate: results from the earth radiation budget experiment, J. Science., 243, 57-63.

Ramanathan, V., 1987: The role of Earth radiation budget studies in climate and general circulation research, J. Geophys. Res., 92, 4075-4095.

Randall, D. A., Harshvardhan, D. A. Dazlich, and Thomas G. Gorsetti, 1989: Interactions among radiation, convection and large-scale dynamics in a general circulation model, $J$. Atmos. Sci., 46, 1943-1970.

Raschke, E., A. Omura, W. B. Rossow, E. B. Carlson, Y.C., Zang, C. Stubenrauch, M. Kottek, and M. Wild, 2005: Cloud effects on the radiation budget based on ISCCP data (1991 to 1995), Int. J. Climatol., 25, 1103-1125.

Rose, F., T. P. Charlock, D. A. Rutan, and G. L. Smith, 1997: Tests of a constraint algorithm for the surface and atmospheric radiation budget, Proceedings of the Ninth Conference on Atmospheric Radiation, Long Beach (Feb. 2-7, 1997), AMS, 466-499. 
Schiffer, R.A., and Rossow, W.B., 1983: The International Satellite Cloud Climatology Project (ISCCP): The First Project of the World Climate Research Programme, Bull. Amer. Meteor. Soc., 64, 779-784.

Sohn, B.-J., and E. A. Smith, 1992: The significance of cloud-radiative forcing to the general circulation on climate time scales- A satellite interpretation, J. Atmos. Sci., 49, 845-860.

Stokes, G. M., and S. E. Schwartz, 1994: The atmospheric radiation measurement program: Programatic background and design of the cloud and radiation testbed, Bull. Amer. Meteor. Soc., 75, 1201-1221.

Stuhlmann, R., and G. L. Smith, 1988: A study of cloud-generated radiative heating and its generation of available potential energy, part II: results for a climatological zonal mean January J. Atmos. Sci., 45, 3928-3493.

Trenberth, K. E., and J. M. Caron, 2001: Estimates of meridional atmosphere and ocean heat transports, J. Climate, 14, 3433-3443.

Trenberth, K. E., and D. P. Stepaniak, 2003: Covariability of components of poleward atmospheric energy transports on seasonal and interannual timescale, J. Climate, 15, 3691-3705.

Washington, W. M., and C. L. Parkinson, 1986: An introduction to three-dimensional climate modeling, University Science Books, Mill Valley, CA.

Weaver, C. P, 2003: Efficiency of storm tracks and important climate parameter? The role of cloud radiative forcing in poleward heat transport, J. Geophys. Res., 108, doi:10.1029/2002JD002756. 
Wielicki, B. A., B. R. Barkstrom, E. F. Harrison, B. B. Lee III, G. Louis Smith, and J. E. Cooper, 1996: Clouds and the Earth's radiant energy system (CERES); an earth observing system experiment, Bull. Amer. Meteor. Soc., 77, 853-868.

Yang, S.-K., S. Zhou, and A. J. Miller, 2000: SMOBA: A 3-D daily ozone analysis using $\mathrm{SBUV} / 2$ and TOVS measurements, www.cpc.ncep.gov/products/stratosphere/SMOBA/smoba_doc.html.

Zhang, Y.-C., and W. B. Rossow, 1997: Estimating meridional energy transport by the atmospheric and oceanic general circulations using boundary fluxes, J. Climate, 10, 23582373.

Zwally, H.J., and coauthors, 2002: ICESat's laser measurements of polar ice, atmosphere, ocean, and land, J. Geodynamics, 34, 405-445. 
Figure 1 Seasonal and zonal mean net shortwave irradiance a), net longwave irradiance b), and net shortwave and longwave irradiance c) of the atmosphere under all-sky conditions. The atmospheric shortwave absorptance d) is computed from a) divided by zonal mean solar constant. The net longwave irradiance and net shortwave plus longwave irradiance of the atmosphere under clear-sky conditions are shown by e) and f), respectively.

Figure 2 Comparison of monthly mean downward shortwave (top), longwave (middle) and net atmospheric (bottom) irradiances for Manus (TWP), Southern Great Plains (SGP), and Barrow, AK (NSA) sites. Open circles and closed squares indicate modeled irradiances and observations derived from March 2000 through Feb. 2003, respectively. The error bars indicate maximum and minimum observed values during the 5-year period (March 2000 through Feb. 2005) for the surface down shortwave and longwave and 4-year period (March 2000 through Feb. 2004) for the atmospheric net.

Figure 3 a) Seasonal zonal mean cloud fraction derived from MODIS measurements by the CERES cloud algorithm (Minnis et al. 2003). Data from March 2000 through Feb. 2004 are averaged. b) Monthly zonal mean cloud fraction derived from GLAS 1064nm laser October 2003 data for all clouds (dotted line), those of which optical thickness greater than 0.3 (solid line) and optical thickness greater than 1 (dash-dot line). The cloud optical thickness is derived from GLAS $532 \mathrm{~nm}$ laser data. The cloud fraction derived from MODIS radiances for the same month is shown by the dashed line. c) Difference between the MODIS derived cloud fraction and the GLAS derived cloud fraction. The fraction of clouds of which optical thickness is less than 0.3 is excluded from the GLAS derived cloud fraction. 
Figure 4 Seasonal and zonal mean cloud shortwave radiative effect at TOA a), at the surface b), and to the atmosphere c).

Figure 5 Seasonal and zonal mean cloud longwave radiative effect at TOA a), at the surface b), and to the atmosphere c).

Figure 6 Seasonal and zonal mean cloud radiative effect (shortwave plus longwave) at TOA a), at the surface b), and to the atmosphere c).

Figure 7 Contour of the daily mean cloud shortwave plus longwave effect at TOA (top row) to the atmosphere (second row) and to the surface (third row) for the tropics (30N to $30 \mathrm{~S})$, northern hemisphere mid-latitude (30N to $60 \mathrm{~N})$, southern hemisphere mid latitude (30S to $60 \mathrm{~N})$, the Arctic $(60 \mathrm{~N}$ to $90 \mathrm{~N})$ and the Antarctic (60S to $90 \mathrm{~S})$ as a function of the cloud optical thickness $(\tau)$ and cloud top height in pressure coordinate estimated from July 2002 data. Only single-layer clouds are used. Contours in the forth row indicate the logarithm (base 10) of the 2D normalized histogram of cloud occurrence. Daily mean irradiances are computed by the method discussed in Appendix A except that daytime and nighttime longwave irradiances are weighted by number of samples.

Figure 8 Normalized 2D histogram sorted by net surface irradiance (shortwave+longwave) anomaly divided by monthly mean value and surface enthalpy (latent heat and sensible heat) flux anomaly divided by monthly mean value. The latent heat and sensible heat fluxes are from Hamburg Ocean Atmosphere Parameters and fluxes from Satellite data (HOAPS, Grassl et al. 2000). The anomalies are defined as the deviation of the zonal mean values from the averaged value over the four-year period from March 2000 through 
Dec. 2004. One month of data (March 2000) between $20^{\circ} \mathrm{N}$ and $20^{\circ} \mathrm{S}$ were used for the plot. The solid line indicates linear regression fit. The the slope of the regression line is correlation coefficient is 0.16 .

Figure 9 Seasonal and zonal mean cloud effect to the atmosphere. The effect includes that on the shortwave and longwave irradiances, as well as on the surface latent and sensible heat fluxes (enthalpy flux).

Figure 10 Seasonal and zonal mean atmospheric cloud effect converted to the rate of meridional energy transport by the atmosphere. The solid line indicate the equivalent meridional energy transport including the cloud effect on the net irradiance, surface latent heat, and sensible heat fluxes. The dash-dot line indicates the equivalent meridional enthalpy transport including only the cloud effect on the net irradiance. The positive and negative value indicates, respectively, northward and southward transport.

Figure a1 Monthly and zonal mean cloud top pressure derived from daytime July 2002 MODIS data by the CERES cloud algorithm (Minnis et al. 2003). Only single layer clouds are considered. 
Table 1: Observed and Modeled Annual Mean Irradiance

\begin{tabular}{|c|c|c|c|c|}
\hline \multicolumn{2}{|c|}{$\begin{array}{l}\text { Observation } \\
\mathrm{Wm}^{-2}\end{array}$} & \multirow[t]{2}{*}{$\begin{array}{l}\text { Model } \\
\mathrm{Wm}^{-2}\end{array}$} & \multirow[t]{2}{*}{$\begin{array}{l}\text { Difference } \\
\mathrm{Wm}^{-2}\end{array}$} & \multirow[t]{2}{*}{$\begin{array}{l}\text { Relative } \\
\text { Difference }\end{array}$} \\
\hline Manus (Tropics) & & & & \\
\hline SW TOA Down & 417 & 417 & - & - \\
\hline SW TOA UP & 110 & 111 & 1.1 & 0.010 \\
\hline SW Surface Down & 208 & 228 & 20.5 & 0.099 \\
\hline SW Surface Up & 69 & 17 & - & - \\
\hline SW Atm. Net & $117^{1}$ & 95 & -20.7 & -0.177 \\
\hline LW TOA UP & 219 & 220 & 1.3 & 0.006 \\
\hline LW Surface Down & 420 & 419 & -0.6 & -0.001 \\
\hline LW Surface Up & 469 & 476 & 7.8 & 0.017 \\
\hline LW Atm. Net & -170 & -163 & 7.1 & 0.041 \\
\hline SW+LW Atm. Net & $-53^{1}$ & -68 & -14.6 & -0.274 \\
\hline \multicolumn{5}{|l|}{ SGP (Midlatitude) } \\
\hline SW TOA Down & 343 & 343 & - & - \\
\hline SW TOA UP & 103 & 104 & 1.0 & 0.010 \\
\hline SW Surface Down & 187 & 199 & 12.6 & 0.068 \\
\hline SW Surface Up & 39 & 39 & -0.5 & 0.008 \\
\hline SW Atm. Net & 92 & 78 & -14.1 & -0.154 \\
\hline LW $\quad$ TOA UP & 243 & 243 & 0.2 & 0.008 \\
\hline LW Surface Down & 337 & 326 & -10.8 & -0.032 \\
\hline LW Surface Up & 395 & 402 & 6.6 & 0.017 \\
\hline LW Atm. Net & -185 & -168 & 17.2 & 0.093 \\
\hline SW+LW Atm. Net & -93 & -90 & 3.1 & 0.033 \\
\hline \multicolumn{5}{|l|}{$\overline{\text { Barrow }}$ (Arctic) } \\
\hline SW TOA Down & 196 & 196 & - & - \\
\hline SW TOA UP & 95 & 98 & 3.0 & 0.032 \\
\hline SW Surface Down & 96 & 102 & 6.4 & 0.067 \\
\hline SW Surface Up & 48 & 49 & 1.3 & 0.027 \\
\hline SW Atm. Net & 53 & 45 & -8.1 & -0.153 \\
\hline LW TOA UP & 203 & 205 & 1.8 & 0.009 \\
\hline LW Surface Down & 238 & 238 & -0.3 & 0.001 \\
\hline LW Surface Up & 271 & 271 & 0.0 & 0.000 \\
\hline LW Atm. Net & -171 & -172 & -1.6 & -0.009 \\
\hline SW+LW Atm. Net & -118 & -127 & -9.7 & -0.082 \\
\hline
\end{tabular}

${ }^{1}$ Modeled shortwave upward surface irradiance is used for the computations. 

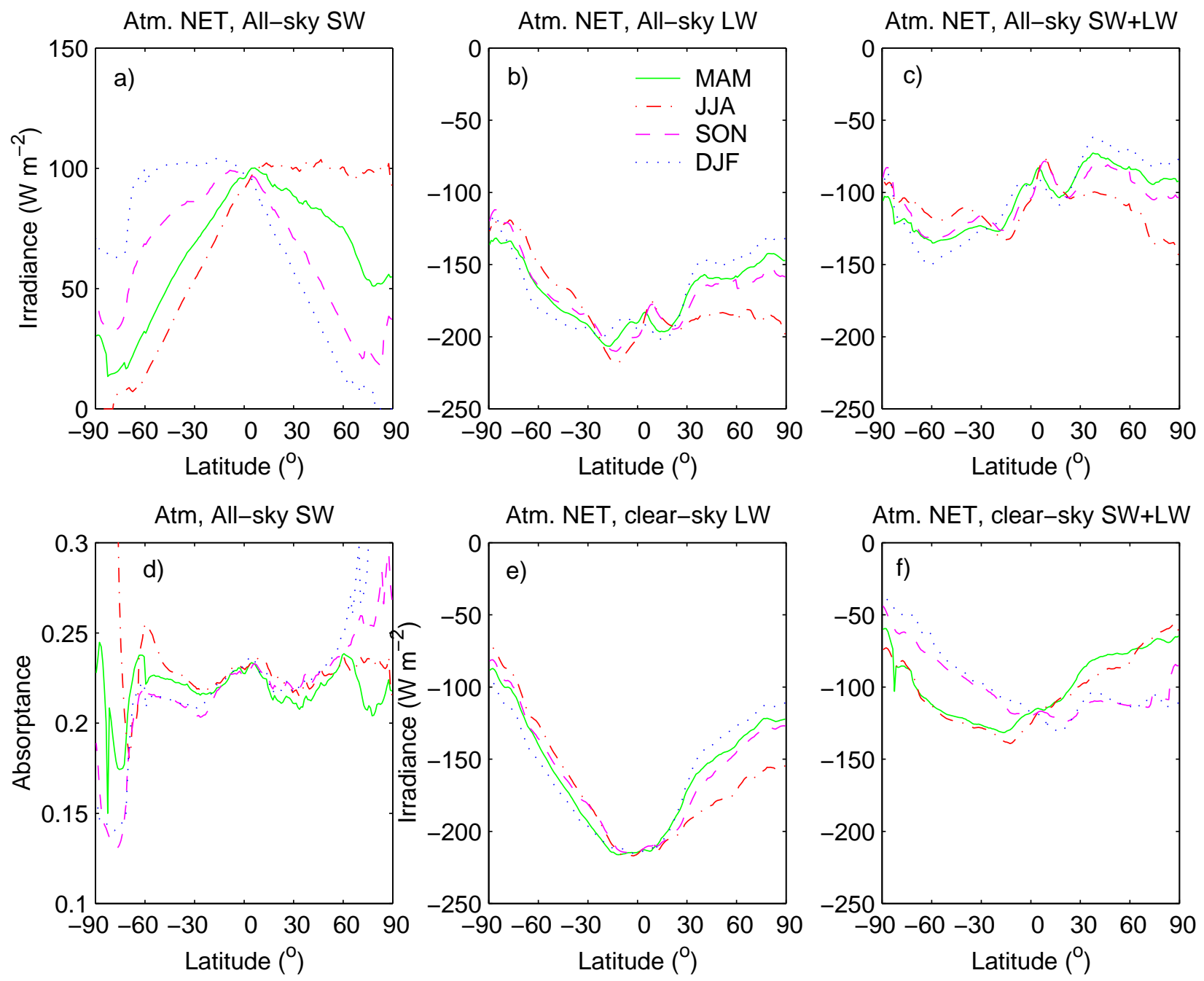

Figure 1 Seasonal and zonal mean net shortwave irradiance a), net longwave irradiance b), and net shortwave and longwave irradiance c) of the atmosphere under all-sky conditions. The atmospheric shortwave absorptance d) is computed from a) divided by zonal mean solar constant. The net longwave irradiance and net shortwave plus longwave irradiance of the atmosphere under clear-sky conditions are shown by e) and f), respectively. 


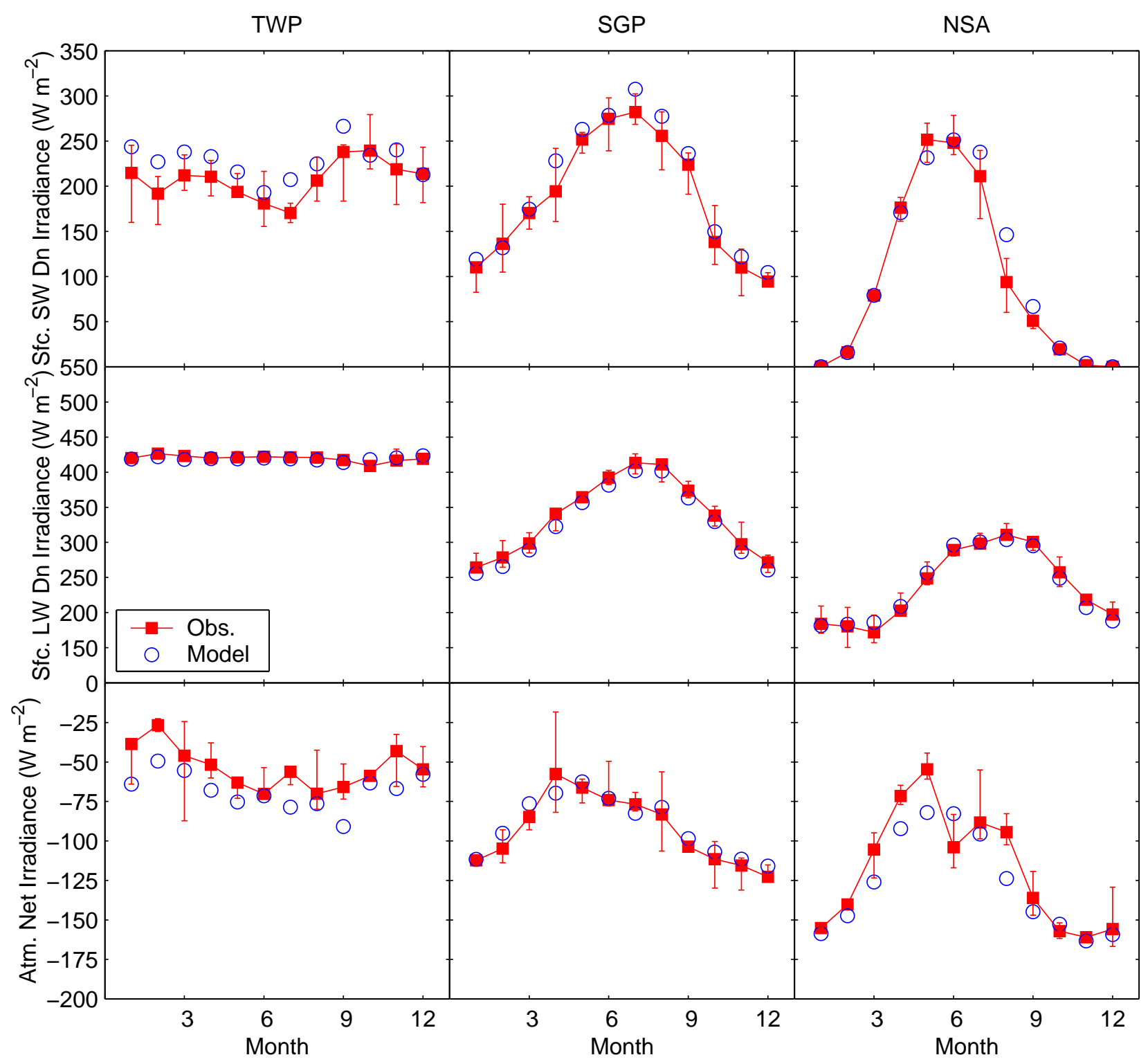

Figure 2 Comparison of monthly mean downward shortwave (top), longwave (middle) and net atmospheric (bottom) irradiances for Manus (TWP), Southern Great Plains (SGP), and Barrow, AK (NSA) sites. Open circles and closed squares indicate modeled irradiances and observations derived from March 2000 through Feb. 2003, respectively. The error bars indicate maximum and minimum observed values during the 5-year period (March 2000 through Feb. 2005) for the surface down shortwave and longwave and 4-year period (March 2000 through Feb. 2004) for the atmospheric net. 

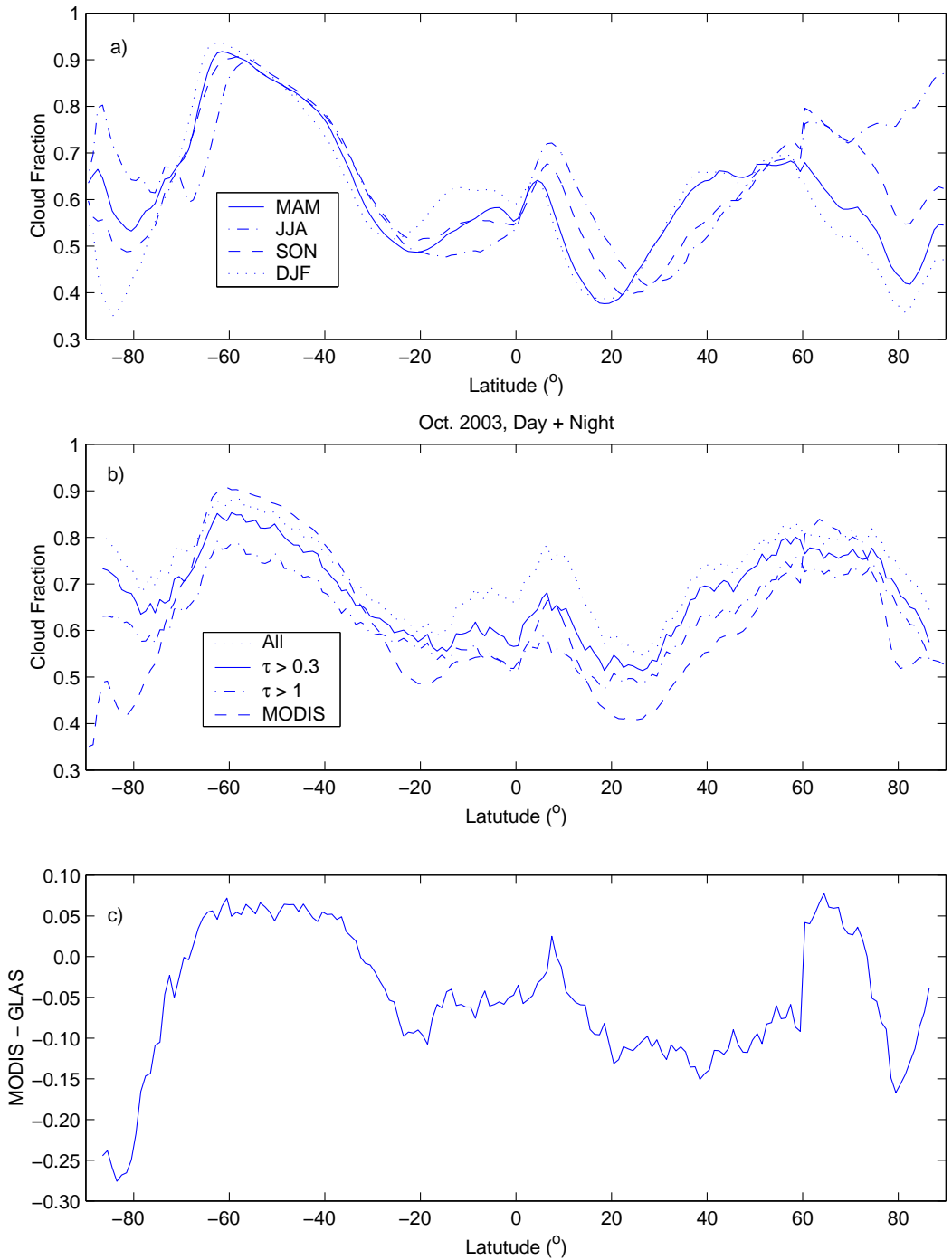

Figure 3 a) Seasonal zonal mean cloud fraction derived from MODIS measurements by the CERES cloud algorithm (Minnis et al. 2003). Data from March 2000 through Feb. 2004 are averaged. b) Monthly zonal mean cloud fraction derived from GLAS 1064nm laser October 2003 data for all clouds (dotted line), those of which optical thickness greater than 0.3 (solid line) and optical thickness greater than 1 (dash-dot line). The cloud optical thickness is derived from GLAS $532 \mathrm{~nm}$ laser data. The cloud fraction derived from MODIS radiances for the same month is shown by the dashed line. c) Difference between the MODIS derived cloud fraction and the GLAS derived cloud fraction. The fraction of clouds of which optical thickness is less than 0.3 is excluded from the GLAS derived cloud fraction. 

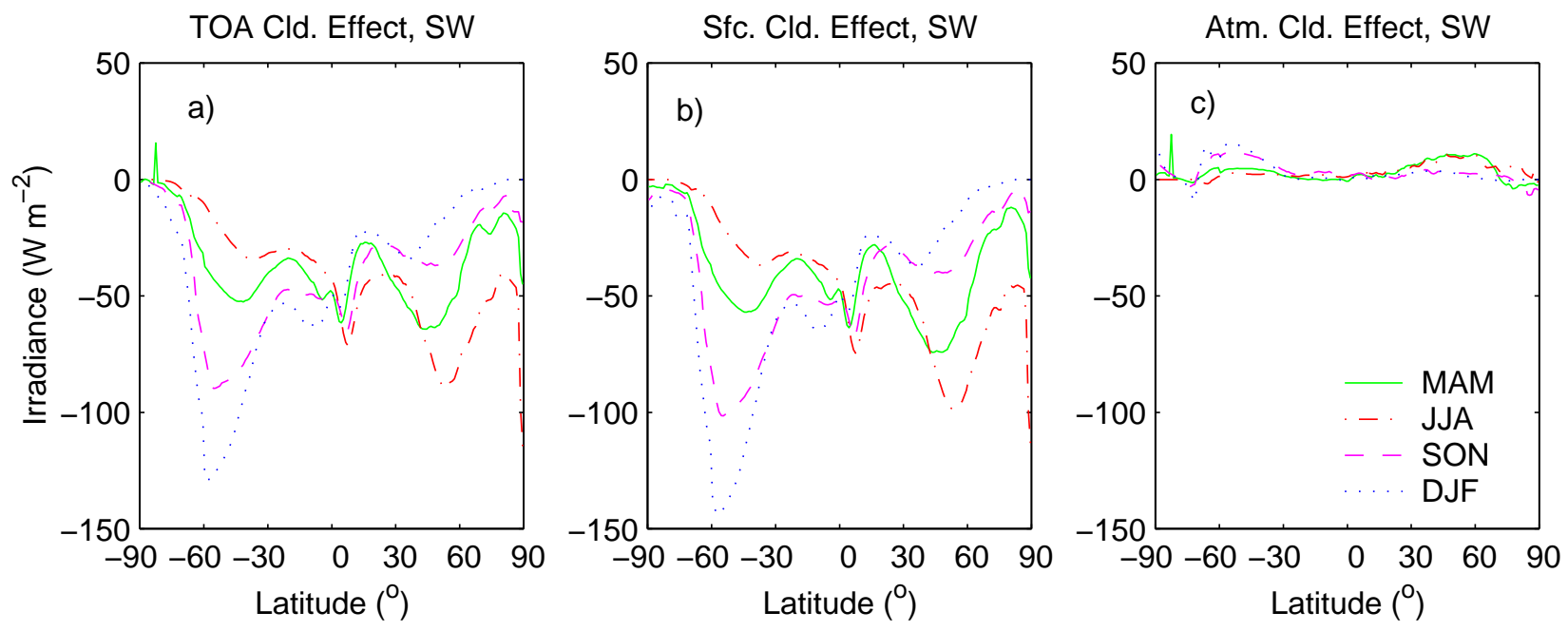

Figure 4 Seasonal and zonal mean cloud shortwave radiative effect at TOA a), at the surface b), and to the atmosphere c). 

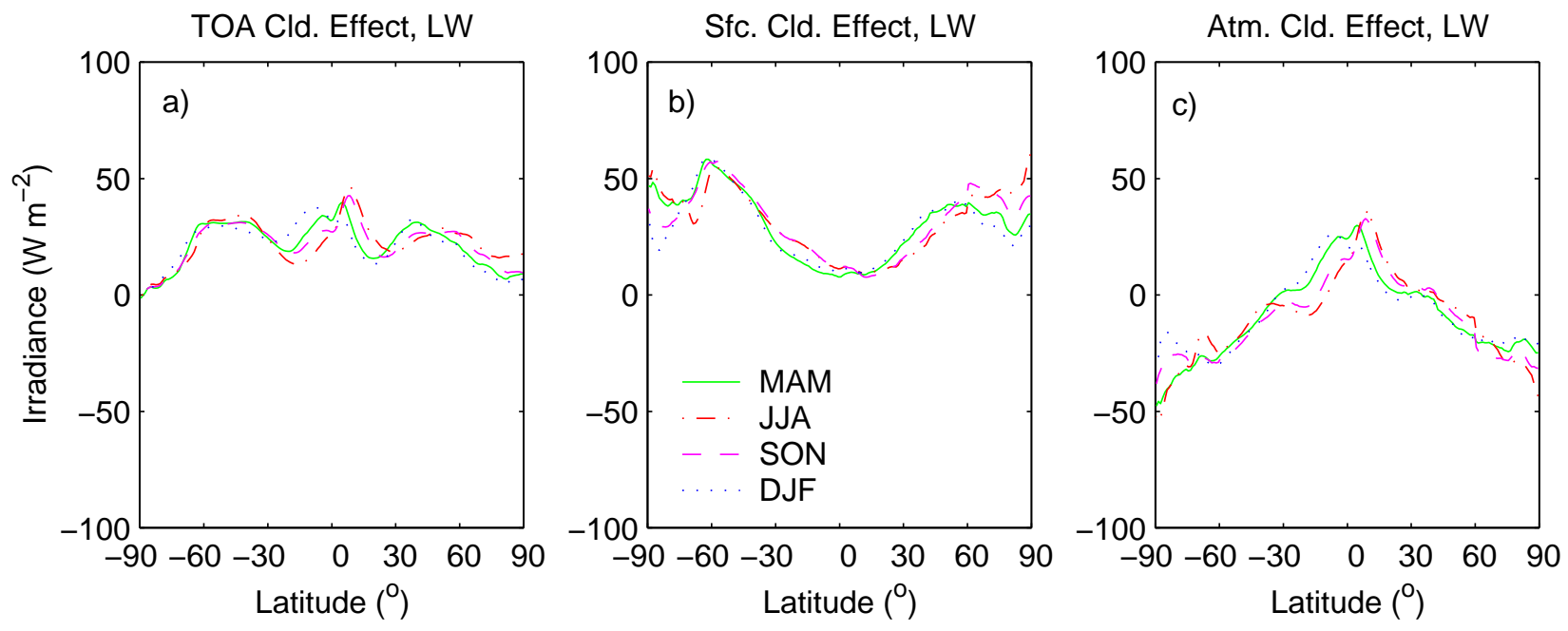

Figure 5 Seasonal and zonal mean cloud longwave radiative effect at TOA a), at the surface b), and to the atmosphere c). 

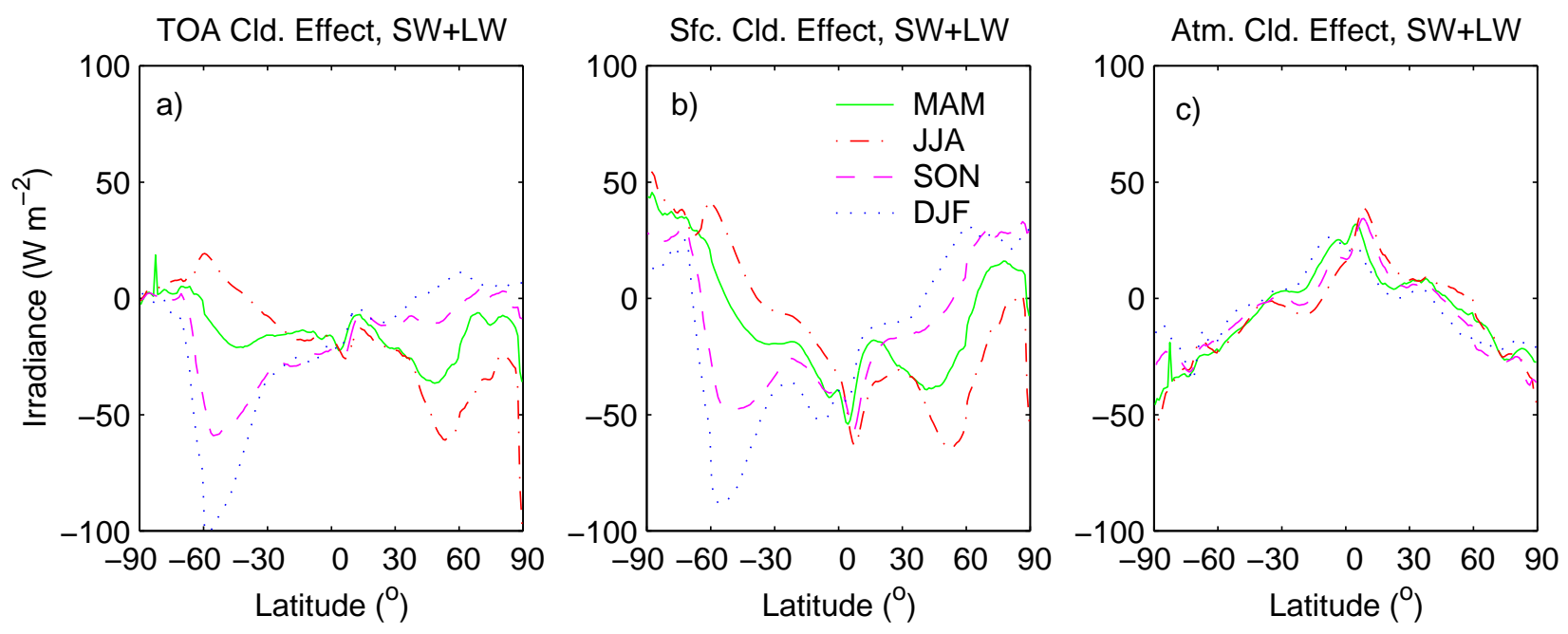

Figure 6 Seasonal and zonal mean cloud radiative effect (shortwave plus longwave) at TOA a), at the surface b), and to the atmosphere $\mathrm{c}$ ). 


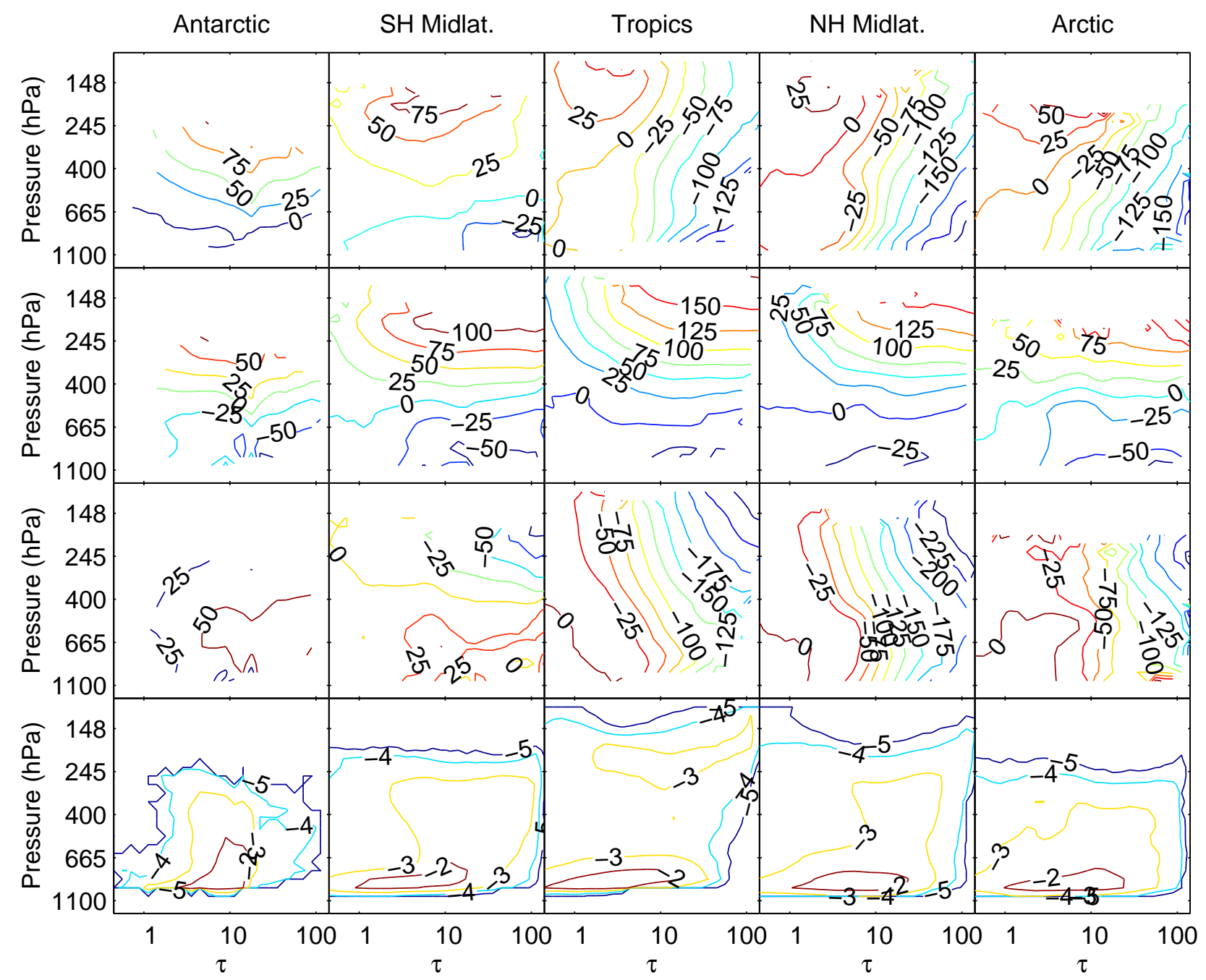

Figure 7 Contour of the daily mean cloud shortwave plus longwave effect at TOA (top row) to the atmosphere (second row) and to the surface (third row) for the tropics (30N to $30 \mathrm{~S})$, northern hemisphere mid-latitude (30N to $60 \mathrm{~N})$, southern hemisphere mid latitude (30S to $60 \mathrm{~N})$, the Arctic (60N to $90 \mathrm{~N})$ and the Antarctic (60S to $90 \mathrm{~S})$ as a function of the cloud optical thickness $(\tau)$ and cloud top height in pressure coordinate estimated from July 2002 data. Only single-layer clouds are used. Contours in the forth row indicate the logarithm (base 10) of the 2D normalized histogram of cloud occurrence. Daily mean irradiances are computed by the method discussed in Appendix A except that daytime and nighttime longwave irradiances are weighted by number of samples. 


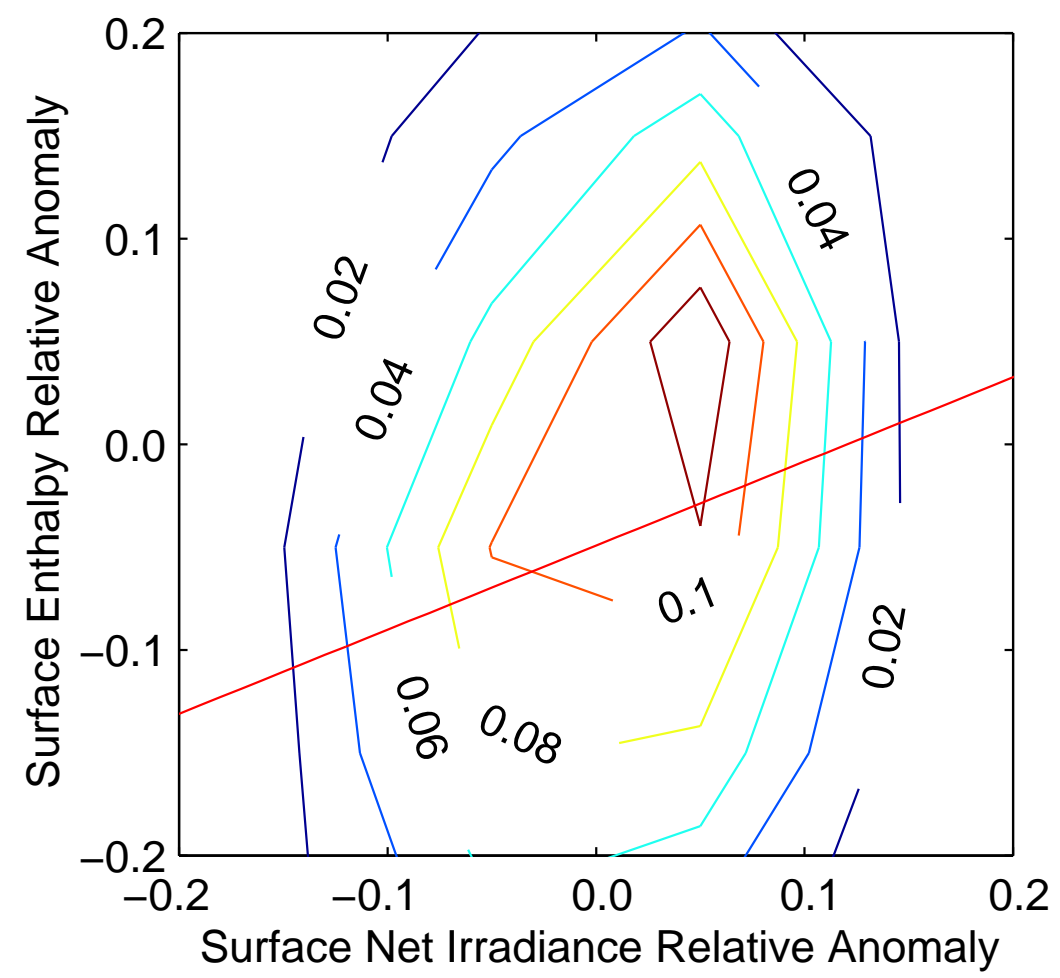

Figure $\mathbf{8}$ Normalized 2D histogram sorted by net surface irradiance (shortwave+longwave) anomaly divided by monthly mean value and surface enthalpy (latent heat and sensible heat) flux anomaly divided by monthly mean value. The latent heat and sensible heat fluxes are from Hamburg Ocean Atmosphere Parameters and fluxes from Satellite data (HOAPS, Grassl et al. 2000). The anomalies are defined as the deviation of the zonal mean values from the averaged value over the four-year period from March 2000 through Dec. 2004. One month of data (March 2000) between $20^{\circ} \mathrm{N}$ and $20^{\circ} \mathrm{S}$ were used for the plot. The solid line indicates linear regression fit. The the slope of the regression line is correlation coefficient is 0.16 . 


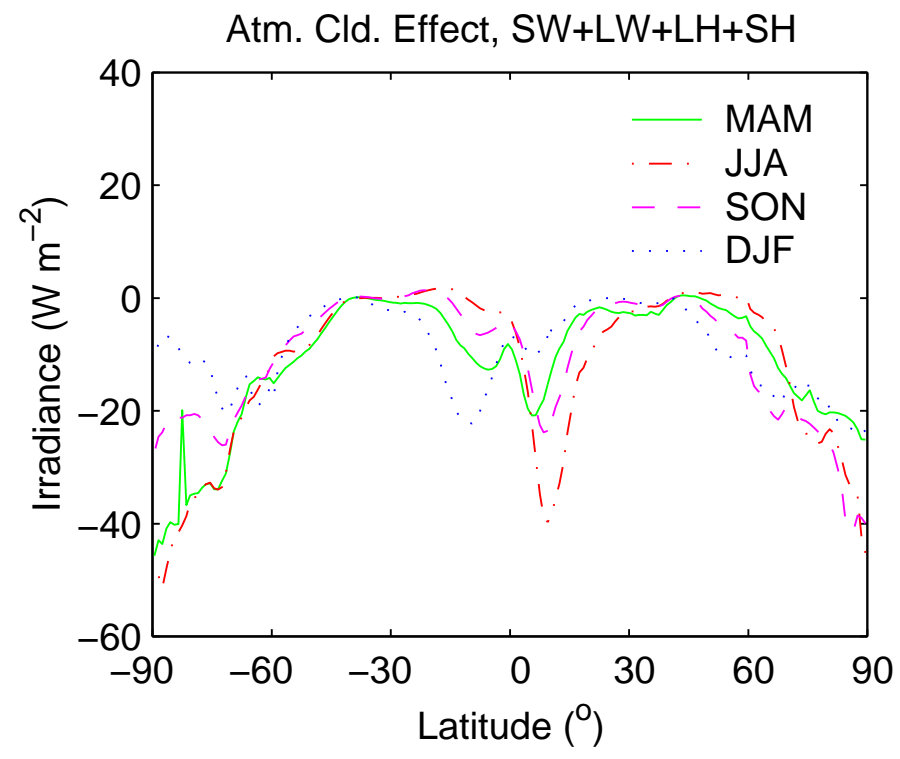

Figure 9 Seasonal and zonal mean cloud effect to the atmosphere. The effect includes that on the shortwave and longwave irradiances, as well as on the surface latent and sensible heat fluxes (enthalpy flux). 

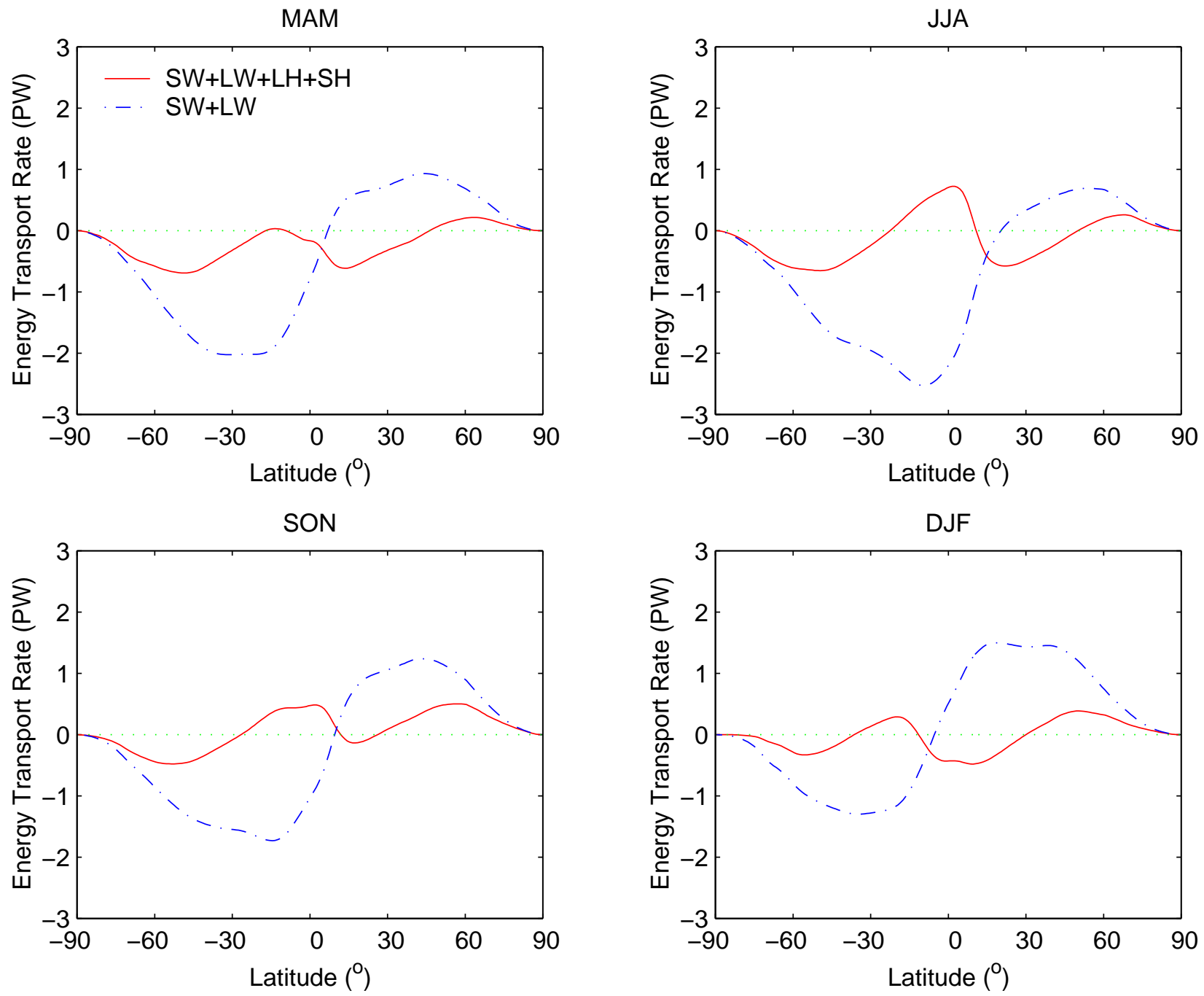

Figure 10 Seasonal and zonal mean atmospheric cloud effect converted to the rate of meridional energy transport by the atmosphere. The solid line indicate the equivalent meridional energy transport including the cloud effect on the net irradiance, surface latent heat, and sensible heat fluxes. The dash-dot line indicates the equivalent meridional enthalpy transport including only the cloud effect on the net irradiance. The positive and negative value indicates, respectively, northward and southward transport. 


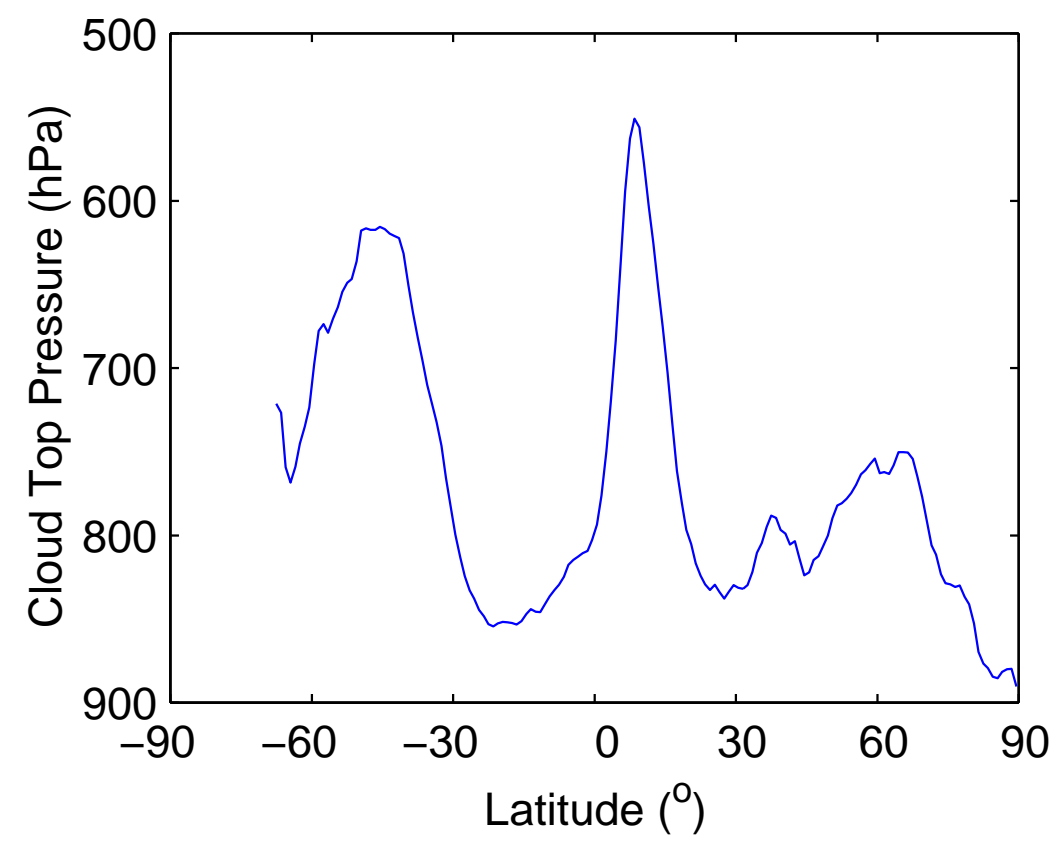

Figure a1 Monthly and zonal mean cloud top pressure derived from daytime July 2002 MODIS data by the CERES cloud algorithm (Minnis et al. 2003). Only single layer clouds are considered. 
